\title{
The Effect of Education on Marital Status and Partner Characteristics: Evidence from the UK
}

\author{
Dan Anderberg \\ $\mathrm{Yu} \mathrm{Zhu}$
}

\section{CESIFO WORKING PAPER No. 3104}

CATEGORY 3: SOCIAL PROTECTION

JUNE 2010

Presented at CESifo Area Conference on Employment And Social Protection, May 2010

\footnotetext{
An electronic version of the paper may be downloaded

- from the SSRN website:

- from the RePEc website:

wWw.SSRN.com

Www.RePEc.org

- from the CESifo website:

www.CESifo-group.org/wp
} 


\title{
The Effect of Education on Marital Status and Partner Characteristics: Evidence from the UK
}

\begin{abstract}
This paper uses a particular school exit rule previously in effect in England and Wales that allowed students born within the first five months of the academic year to leave school one term earlier than those born later in the year. Focusing on women, we show that those who were required to stay on an extra term more frequently hold some academic qualification. Using having been required to stay on as an exogenous factor affecting academic attainment, we find that holding a (low level) academic qualification has no effect on a women's probability of being married, but increases the probability of her husband holding some academic qualification and being economically active.
\end{abstract}

JEL-Code: I10, J12.

Keywords: education, marriage, assortative mating.

Dan Anderberg

Royal Holloway University of London

United Kingdom

Dan.Anderberg@rhul.ac.uk
$\mathrm{Yu} \mathrm{Zhu}$

University of Kent at Canterbury

United Kingdom

Y.Zhu-5@kent.ac.uk

June 17,2010

The authors would like to thank Arnaud Chevalier, Costas Meghir, Jonathan Wadsworth, Stacey Chen and seminar participants at Kent, Sheffield, and CESifo for helpful comments, and Vikesh Amin for excellent research assistance. 


\section{Introduction}

Two stylized facts regarding the relationship between education and marriage are very well known. First, individuals who invest more in education tend to marry more educated partners than those who invest less, i.e. there is a positive assortative mating on education. Second, while individuals who invest more in education tend to marry later in life, at higher ages they are nevertheless more are more likely to be married.

The positive assortative mating in the marriage market has led to a popular argument that one part of an individual's economic return to acquiring education obtains through an increased probability of marrying a more qualified and higher-earning spouse. Indeed, this argument was made forcefully by Claudia Goldin (1992) who went so far as to argue that improving the chances of marrying a college-educated man was the main motive for women for entering college. The hypothesis that by acquiring education an individual can affect the identity of his/her future spouse however assumes that education has a causal effect on the individual's marriage outcome. This is not implied by the observed positive assortative mating: whom an individual marries may well be determined by factors such as social background, geographic location, etc., factors that are also correlated with education, and could lead the observed correlation in spouses' education to be partly or wholly spurious.

In this paper we present new evidence on the effect of education on marital outcomes for women using UK data. To do so we exploit a particular historical feature of the educational system in England and Wales. In particular, we use that, in the past, individuals who were born in the first five months of the academic year (September through January) were allowed to leave school at the end of the spring term in the year in which they reached the compulsory schooling age of 16, whereas those born in the remaining seven months (February through August) had to stay on for one more term. For the academic cohorts that we consider, this feature, due to its interaction with the timing of examinations, implied a substantial effect of date of birth on academic attainment: those born after the January-February threshold date are significantly 
more likely to hold some academic qualification than those born before the threshold date $1^{1}$ Our identification strategy will hence involve exploring how marital outcomes vary with month of birth, and to relate those differences to the observed differences in academic attainment. The main findings from the paper can be summarized as follows. Using data on individuals belonging to 14 academic cohorts born between September 1957 and August 1971 from the UK Labour Force Survey we find that:

- Women born after the January-February threshold date (who were required to stay on for one more term) are close to four percentage points more likely to hold some academic qualification than those born before the threshold.

- Holding an academic qualification does not affect the probability of a woman being currently married: women born before the threshold are as likely to be currently married as women born after the threshold.

- Holding an academic qualification does affect the properties of a woman's spouse: women born after the threshold date are more likely to be married to men who hold some academic qualification and are economically active.

Since the social structures of marriage were first brought to light, much effort has been devoted to measuring marital patterns across time, countries and subgroups of the population.2 Despite this substantial literature, surprisingly little is known about to what extent an individual's education choice affects her marital outcomes. Indeed, only a very small literature has applied statistical techniques that have allowed causal interpretations for the findings regarding the impact of education. Here we briefly review this modest literature.

Looking first at the effect of education on marital status, there appears to be a short-run effect of staying in school longer, consistent with individuals delaying marriage; however, turning to marital status later in life, education appears to have little or no effect on the probability of

\footnotetext{
${ }^{1}$ Del Bono and Galindo-Rueda (2006), focusing on the wage returns to education, present similar finding using, in part, the same data.

${ }^{2}$ For early studies of marital patterns, see Hunt (1940), Burgess and Wallin (1943) and Rockwell (1976).
} 
an individual being married. E.g. Duflo et al. (2010), using data from Kenya, investigate the effect of an educational program which reduced the cost of education by providing free school uniforms. The program was implemented among students enrolled in grade 6 in 2003, and was found to have reduced the probability of girls being married two years later. Similarly, Kirdar et al. (2010) exploit the extension of compulsory schooling in Turkey from five to eight year in 1997. Their find that the schooling reform brought about a reduction in the frequency of young (by age 17) marriages. In contrast, the analysis of Fort (2007) suggests that any effect of increased schooling on timing of marriage must have been short: exploiting the 1963 reform act in Italy which increased the minimum school leaving age from 11 to 14 , Fort finds no causal effect of education on probability of age at first marriage between ages 18-26. Turning to even longer horizons, Breierova and Duflo (2004) make use of a large school construction program in Indonesia between 1973 and 1978, the timing of which varied across regions. Using data from the 1995 Indonesiam Intercensal Survey and focusing on women, the authors found that increased education leads to a higher age at first marriage, but has no impact on the probability of a woman being currently married. Further evidence suggesting no significant long run effect of education on marital status is provided by Lefgren and McIntyre (2006) who, following the approach of Angrist and Krueger (1991), use quarter of birth as instrument for educational attainment, applied on U.S. Census data. While their point estimate for the causal effect of an additional year of education on the probability of a woman being married on census day is negative, the effect is statistically insignificant.

Even less is known about to what extent positive assortative mating on education can be given a causal interpretation, i.e. to what extent an increase in an individual's education leads her to marry a more qualified spouse. However, the evidence that does exist suggests a positive causal effect. Behrman and Rosenzweig (2002) use data on 600 married female monozygotic twins from the Minnesota Twins Registry. They show that the correlation between spouses' education is significantly lower when using variation in education within twins pairs than when using cross-sectional variation. Nevertheless the authors still find that a woman's education has a causal effect on the schooling of her spouse: a one-year increase in schooling for a woman 
increases the schooling of her spouse by little less than 0.4 of a year. Using the same technique on Norwegian administrative data on married siblings and twins-pairs, Oreopoulous and Salvanes (2009) find that a one year increase in an individual's education increases the spouse's length of schooling by about 0.23 of a year. Lefgren and McIntyre (2007) using quarter of birth as instrument (see above) finds that an extra year of education increases husband's earnings by about $\$ 4,000$. Relatedly, McCrary and Royer (2006) use natality data from California and Texas, which includes information on the mother's exact date of birth. They show that women born just after the state school entry cut-off date have less education and also less educated partners.

The rest of the paper is outlined as follows. The next section discusses the conceptual and identification issues using a simple theoretical model. Section III details the institutional context. After describing the data in Section IV, we present our main results in Section V. Section VI concludes.

\section{Conceptual Issues: Equilibrium Education and Marriage}

What are the channels through which an individual's choice of education can have a causal effect on her marital outcome? There are three distinct possibilities: (i) an individual's education may impact on how many potential partners she meets; (ii) it may impact on which potential partners she meets; (iii) it may affect the likelihood of any given match leading to marriage.

There are relatively few available theoretical models of marriage markets with pre-marital investments in education. A recent exception is Chiappori et al. (2009) ${ }^{3}$ They model a frictionless marriage market in the style of Becker $(1973,1991)$. Hence, in terms of the three channels outlined above, their model focuses on the last channel. Here we sketch a model with frictions which allows for channel (ii). The essentials of the model are as follows. Each individual is associated with a set of background characteristics (ability, parental income, etc) which play two roles: (i) they affect the individual's cost of education, and (ii) they may directly affect the individual's (equilibrium) probability of matching with a skilled potential partner.

\footnotetext{
${ }^{3}$ See also Peters and Siow (2002).
} 
The individual's education choice may also impact on her chance of matching with a skilled potential partner. A match may be turned down on economic grounds due to asymmetry in earnings. The model thus generally features assortative mating, which may or may not have a causal interpretation. The purpose of the model is primarily to aid the discussion of empirical identification. To that end, the model includes an instrumental variable, uncorrelated with the individual's other characteristics, which only affects the cost of education.

The main results to take away from the analysis are the following. First, the effect of education on the probability of marriage is generally heterogenous in the population. Second, a key requirement for the instrumental variable is that it must not directly affect with whom an individual matches, a requirement discussed in some detail below. Third, if the instrumental variable does satisfy this requirement, then it is possible to identify an average effect of education on the probability of marriage. Fourth, if furthermore, if education has no impact on the marriage probability (for those whose education decisions strictly depend on the instrument), it is also possible to identify an average effect of education on partner's skill level.

\section{A Simple Model of Education and Marriage}

Consider an economy with continuums (of equal size) of women and men 4 For notational simplicity ignore gender differences. Each individual $i$ is associated with an $k$-dimensional vector of characteristics $\alpha_{i}$ which has a discrete distribution, represented by a p.d.f. $f(\boldsymbol{\alpha})$ defined over a support $A$. There is also a binary instrumental variable $z_{i} \in\{0,1\}$. A key assumption is that $z_{i}$ is independent of the individual's other characteristics.

Assumption 1 The instrument is independent of the individual's other characteristics, $z_{i} \perp \alpha_{i}$.

Individual $i$ decides whether or not to invest in education, $x_{i} \in\{0,1\}$. The individual's investment cost, denoted $c\left(\boldsymbol{\alpha}_{i}, z_{i}\right)$, is, for simplicity, modelled as a direct utility cost.

Assumption 2 The instrument reduces the cost of education, $c\left(\boldsymbol{\alpha}_{i}, 1\right)<c\left(\boldsymbol{\alpha}_{i}, 0\right)$ for all $\alpha_{i} \in A$.

\footnotetext{
${ }^{4}$ The current model draws in part on the model by Lommerud and Konrad (2008).
} 
After deciding on education, individual $i$ meets with one potential partner, denoted $-i$. The potential partner, $-i$, may be either skilled or unskilled, $x_{-i} \in\{0,1\}$.

Assumption 3 The probability that individual $i$ matches with a skilled potential partner depends on her characteristics and on her skill level and is denoted $p\left(\boldsymbol{\alpha}_{i}, x_{i}\right)$.

Note that $p\left(\boldsymbol{\alpha}_{i}, x_{i}\right)$ is an equilibrium probability. The crucial aspect of Assumption 3 is that $z_{i}$ does not directly affect the equilibrium probability of matching with a skilled partner.

The match between $i$ and $-i$ is associated with match quality $\theta_{i} \in R$ which enters the utility of both partners additively if they marry. $\theta_{i}$ is a continuous random variable which is i.i.d. across potential couples, and with c.d.f. $G\left(\theta_{i}\right)$. The skill level of individual $i$ determines her earnings $y_{i} \in\left\{y_{0}, y_{1}\right\}$ where $y_{1}>y_{0}$. If individual $i$ does not marry, her consumption is her own earnings $c_{i}=y_{i}$. If she does marry, then her consumption is $c_{i}=(1-\gamma) y_{i}+\gamma y_{-i}$ where $\gamma \in[0,1 / 2]$ indicates the degree of consumption sharing which is assumed to be positive and fixed.

\section{The Marriage Decision}

Individual $i$ will agree to marry $-i$ if and only if $(1-\gamma) y_{i}+\gamma y_{-i}+\theta_{i} \geq y_{i}$. However, for the match to lead to marriage, $-i$ must also agree to marry $i$. Trivially, if they have the same skill level, they marry if and only if $\theta_{i} \geq 0$. If one is skilled and one is unskilled, they marry if and only if $\theta_{i} \geq \gamma \Delta y \geq 0$ where $\Delta y \equiv y_{1}-y_{0}$. Define $\pi_{s} \equiv 1-G(0)$ and $\pi_{m} \equiv 1-G(\gamma \Delta y)$ as the probability of marriage conditional on a "skill-symmetric" $(s)$ match and a "mixed-skill" $(m)$ match, respectively, with $\pi_{s} \geq \pi_{m}$.

\section{The Investment Decision}

The benefit to individual $i$ from investing in education is given by the change in expected utility from consumption and match quality 5 This can be written is

$$
B\left(\boldsymbol{\alpha}_{i}\right) \equiv \Delta y+\left(\theta_{s}-\theta_{m}\right)\left\{p\left(\boldsymbol{\alpha}_{i}, 1\right)-\left[1-p\left(\boldsymbol{\alpha}_{i}, 0\right)\right]\right\}-\gamma \pi_{m} \Delta y\left\{\left[1-p\left(\boldsymbol{\alpha}_{i}, 1\right)\right]+p\left(\boldsymbol{\alpha}_{i}, 0\right)\right\}
$$

\footnotetext{
${ }^{5}$ Formally the benefit $B\left(\boldsymbol{\alpha}_{i}\right)$ is defined as the difference $E\left[c_{i}+\theta m_{i} \mid \boldsymbol{\alpha}_{i}, x_{i}=1\right]-E\left[c_{i}+\theta m_{i} \mid \boldsymbol{\alpha}_{i}, x_{i}=0\right]$.
} 
where $\theta_{s} \equiv E\left[\theta I_{\theta \geq 0}\right]$ and $\theta_{m} \equiv E\left[\theta I_{\theta \geq \gamma \Delta y}\right]$ (where $I_{S}$ is the indicator function which is unity if $S$ is true and zero otherwise), with $\theta_{s}>\theta_{m}$. The first term in (1) is the earnings increase. The second term is non-negative if investing in education increases the probability of a skill-symmetric match. The third component is non-positive since the individual may suffer a consumption sharing loss when skilled, whereas she may gain from consumption sharing when unskilled.

Individual $i$ invests if and only if the benefit exceeds the cost; formally, $x\left(\boldsymbol{\alpha}_{i}, z_{i}\right) \equiv I_{B\left(\boldsymbol{\alpha}_{i}\right) \geq c\left(\boldsymbol{\alpha}_{i}, z_{i}\right)}$. Note that even cost-irrelevant personal characteristics may affect the individual's education decision. Since $z_{i}$ reduces the cost of education, there will generally be a set of types who invest if and only if $z_{i}=1$. Hence define the (equilibrium) set

$$
A^{*} \equiv\left\{\boldsymbol{\alpha}_{i} \in A \mid x\left(\boldsymbol{\alpha}_{i}, 1\right)=1 \text { and } x\left(\boldsymbol{\alpha}_{i}, 0\right)=0\right\}
$$

and assume that this a non-empty subset of $A$. Following Angrist et al. (1996) we refer to $A^{*}$ as the set of "compliers".

\section{Equilibrium}

While it is not necessary for the current purposes to characterize the details of the equilibrium, we will outline what doing so would entail. To complete the model, the matching technology would need to be specified. As an example, suppose that $\boldsymbol{\alpha}_{i}$ and $x_{i}$ are summarized in an unidimension index $\mathcal{I}_{i}=\boldsymbol{\beta} \alpha_{i}+\delta x_{i}+\varepsilon_{i}$ for some vector $\boldsymbol{\beta}$, scalar $\delta$, and "error" $\varepsilon_{i}$ (unknown to the individual when deciding on education) and assume that individuals match by rank of $\mathcal{I}_{i}$. If $\delta=0$, this simply leads to a correlation between $\alpha_{i}$ and $\alpha_{-i}$. When $\delta>0$, individual $i$ can increase $\mathcal{I}_{i}$ by investing in skills and hence affect the probability distribution over $\alpha_{-i}$ and $x_{-i}$. Turning to the description of an equilibrium, the probability function $p(\boldsymbol{\alpha}, x)$ depends on the investment function $x(\boldsymbol{\alpha}, z)$ via the matching technology; conversely, individual behaviour $x(\boldsymbol{\alpha}, z)$ depends on $p(\boldsymbol{\alpha}, x)$. An equilibrium (corresponding to a fixed point) consists of two mutually consistent functions 6

\footnotetext{
${ }^{6}$ In principle, an equilibrium may be in mixed strategies. However, we assume the existence of a pure strategy equilibrium.
} 


\section{The Effect of Education on Marital Outcomes}

Let $\mu\left(\boldsymbol{\alpha}_{i}, x_{i}\right)$ denote marriage probability of individual $i$ given her characteristics and skill level. The effect of education on the marriage probability of individual $i$ is then

$$
\Delta \mu\left(\boldsymbol{\alpha}_{i}\right) \equiv \mu\left(\boldsymbol{\alpha}_{i}, 1\right)-\mu\left(\boldsymbol{\alpha}_{i}, 0\right)=\left\{p\left(\boldsymbol{\alpha}_{i}, 1\right)-\left[1-p\left(\boldsymbol{\alpha}_{i}, 0\right)\right]\right\}\left(\pi_{s}-\pi_{m}\right),
$$

which may be either positive or negative and is generally heterogenous in the population. E.g. a characteristic that increases the individual's chances of matching with a skilled potential partner (for either own skill level) will increase the individual effect of education on the probability of marriage. There are two cases in which education has no impact on the marriage probability of individual $i$ : (i) when there is no income sharing $(\gamma \rightarrow 0)$ and all marriages are entirely "lovebased", and (ii) when the probability of a "skill-symmetric match" is the same for both skill levels: $p\left(\boldsymbol{\alpha}_{i}, 1\right)=1-p\left(\boldsymbol{\alpha}_{i}, 0\right)$. Note that while the first case implies that the effect of education on the marriage probability is zero for everyone, the latter condition may hold for some types but not for others.

Consider next the effect of education on the partner's skill level. Since we will only observe the partners to married individuals, we interpret the effect of education on partner's skill level for individual $i$ as the difference in the probability of her partner being skilled, conditional on her being married $]^{7}$ This is given by

$$
\Delta x_{-i}\left(\boldsymbol{\alpha}_{i}\right) \equiv \frac{p\left(\boldsymbol{\alpha}_{i}, 1\right) \pi_{s}}{\mu\left(\boldsymbol{\alpha}_{i}, 1\right)}-\frac{p\left(\boldsymbol{\alpha}_{i}, 0\right) \pi_{m}}{\mu\left(\boldsymbol{\alpha}_{i}, 0\right)}
$$

A sufficient condition for $\Delta x_{-i}\left(\boldsymbol{\alpha}_{i}\right)$ to be strictly positive is that $p\left(\boldsymbol{\alpha}_{i}, 1\right) \geq p\left(\boldsymbol{\alpha}_{i}, 0\right)$ and $\pi_{s} \geq \pi_{m}$, with at least one of the inequalities being strict. Hence as long as (i) investing in education leads to a better chance of matching with a skilled potential partner, and (ii) skill-symmetric matches having a higher acceptance rate than mixed-skill matches, education

\footnotetext{
${ }^{7}$ Formally, we define the effect of education on the partner's skill level as

$$
\Delta x_{-i}\left(\boldsymbol{\alpha}_{i}\right) \equiv \operatorname{Pr}\left(x_{-i}=1 \mid m_{i}=1, \boldsymbol{\alpha}_{i}, x_{i}=1\right)-\operatorname{Pr}\left(x_{-i}=1 \mid m_{i}=1, \boldsymbol{\alpha}_{i}, x_{i}=0\right) .
$$
}

Expression (40 follows from applying Bayes' rule. 
will have a positive effect on partner skill level. Note that $\Delta x_{-i}\left(\boldsymbol{\alpha}_{i}\right)$ can be non-zero even if education has no effect on the individual's marriage probability.

\section{Identification}

Assume now that we have a random sample of women. For each woman we observe her marital status $m_{i}$, skill level $x_{i}$, instrument $z_{i}$, and, if married, the skill level of her partner, $x_{-i}$. We assume here that $\boldsymbol{\alpha}_{i}$ is completely unobserved. Given that $z_{i}$ only influences $m_{i}$ via $x_{i}$ an IV approach can be expected to identify the effect of education on marriage. To this end, note that, using the law of iterated expectations, $E\left[m_{i} \mid z_{i}\right]=E\left[\mu\left(\boldsymbol{\alpha}_{i}, x\left(\boldsymbol{\alpha}_{i}, z_{i}\right)\right) \mid z_{i}\right]$. Taking the difference of this expectation between $z_{i}=1$ and $z_{i}=0$, exploiting the independence of $\boldsymbol{\alpha}_{i}$ and $z_{i}$ and noting that only compliers contribute to this difference, yields $E\left[\Delta \mu\left(\boldsymbol{\alpha}_{i}\right) \mid \boldsymbol{\alpha}_{i} \in A^{*}\right]$. $\sum_{\boldsymbol{\alpha}_{i} \in A^{*}} f\left(\boldsymbol{\alpha}_{i}\right)$. By a similar logic, $E\left[x_{i} \mid z_{i}=1\right]-E\left[x_{i} \mid z_{i}=0\right]=\sum_{\boldsymbol{\alpha}_{i} \in A^{*}} f\left(\boldsymbol{\alpha}_{i}\right)$ measures the fraction of compliers in the population. Hence, following the logic of Imbens and Angrist (1994), we have that

$$
\frac{E\left[m_{i} \mid z_{i}=1\right]-E\left[m_{i} \mid z_{i}=0\right]}{E\left[x_{i} \mid z_{i}=1\right]-E\left[x_{i} \mid z_{i}=0\right]}=E\left[\Delta \mu\left(\boldsymbol{\alpha}_{i}\right) \mid \boldsymbol{\alpha}_{i} \in A^{*}\right]
$$

The IV/Wald estimator, which replaces the expectations on the left hand side with the corresponding sample means, is hence a consistent estimator for the average effect of education on marriage probability among compliers.

Identification of the effect of education on partner's skill level is complicated not only by endogeneity of $x_{i}$ but also by selection into marriage. In the absence of a second instrumental variable (affecting marriage probability), we can identify the effect of education on partner's skill level under the assumption that education does not affect the probability of an individual being married. However, we do not need to assume that the probability of marriage is skill-independent for everyone: under the IV strategy, we only need the marriage probability to be skill-independent for those types whose education decisions are actually affected by the instrument.

Assumption 4 The marriage probability is skill-independent for all compliers: $\mu\left(\boldsymbol{\alpha}_{i}, 1\right)=$ 
$\mu\left(\boldsymbol{\alpha}_{i}, 0\right)=\widehat{\mu}\left(\boldsymbol{\alpha}_{i}\right)$ for all $\boldsymbol{\alpha}_{i} \in A^{*}$.

Assumption 4 implies that $E\left[m_{i} \mid z_{i}\right]$ is independent of $z_{i}$ which is of course what is tested by the IV/Wald estimator of the effect of education on marriage probability. Under Assumption 4 it can be shown that

$$
\frac{E\left[x_{-i} \mid m_{i}=1, z_{i}=1\right]-E\left[x_{-i} \mid m_{i}=1, z_{i}=0\right]}{E\left[x_{i} \mid m_{i}=1, z_{i}=1\right]-E\left[x_{i} \mid m_{i}=1, z_{i}=0\right]}=E_{\widehat{f}}\left[\Delta x_{-i}\left(\boldsymbol{\alpha}_{i}\right) \mid \boldsymbol{\alpha}_{i} \in A^{*}\right],
$$

where the notation $\widehat{f}$ indicates that the expectation over $\boldsymbol{\alpha} \in A^{*}$ is taken using the marriageprobability weighted density (which is defined only for compliers and under Assumption 4) $\widehat{f}\left(\boldsymbol{\alpha}_{i}\right) \equiv \widehat{\mu}\left(\boldsymbol{\alpha}_{i}\right) f\left(\boldsymbol{\alpha}_{i}\right) / \sum_{\boldsymbol{\alpha} \in A^{*}} \widehat{\mu}(\boldsymbol{\alpha}) f(\boldsymbol{\alpha})$ rather than the standard conditional density. The IV/Wald estimator, which replaces the expectations on the left hand side with the corresponding sample means, is hence, under Assumption 4, a consistent estimator for the (weighted) average effect of education on partner skill level among compliers.

\section{Further Issues}

The above model, while fairly general, does contain a few restrictive features. First, it assumes that education preceeds marriage. In the analysis below, we will use as education measure an indicator for whether an individual holds any academic qualification. Since this is typically determined by exam taken at the age of 16 in the UK, we perceive this to be a negligable issue. Second, the model assumes that each individual meets precisely one potential partner. This reduces "competition" in the marriage market relative to cases where individuals meet multiple potential partners. Nevertheless, we believe that the identification strategy would continue to be valid in more general settings.

A crucial, but somewhat subtle, assumption in the model is that the instrument $z_{i}$ affects the probability of matching with a skilled potential partner only via the individual's chosen education. This is non-trivial requirement that will fail for some commonly used instruments for educational attainment. Consider e.g. using the raising of a school leave age as instrument for education. The instrument $z_{i}$ would be "switched on" for birth cohorts born after a certain date. However, since an individual's birth-cohort constitutes a marriage-market relevant social 
grouping, the instrument will directly affect the probability of matching with a skilled potential partner. Intuitively, comparing the marriage outcomes of individuals born before and after the cutoff birth date for being affected by the raising of the school leaving age will confound individual effects of education with general equilibrium effects of an increased level of education in the marriage market. The same comments apply to e.g. distance to college when marriage markets have a geographical dimension. The current setting where there is an educationalattainment relevant threshold date within the academic year hence provide a unique opportunity to study the effect of academic qualifications on marital outcomes ${ }^{8}$

\section{Institutional Context}

The school education system in the UK is divided into three stages: primary education, compulsory secondary education and post-compulsory secondary education. While the education and training systems of England, Wales and Northern Ireland are broadly similar, the education system in Scotland has always been completely independent with its own laws and practices. In the following, we will focus on the education system in England, Wales and Northern Ireland.

\section{School Entry Policy}

The academic year runs from September 1 to August 31 with three terms starting in September, January, and April, respectively. By UK law, all children of compulsory school age (between 5 and 16) must receive a full-time education. In England and Wales, children must start school at the beginning of the term after they turn 5. There is, however, significant variation in admissions policies across local education authorities (LEAs). While the statutory policy is adopted by only around $1 \%$ of LEAs, most LEAs operate a triple-entry-point system that admits children

\footnotetext{
${ }^{8}$ Note that even using date of birth relative to the cutoff date between academic cohorts (in our case, the August-September threshold) could fail the identifying assumption in so far as an individual's academic cohort constitute a marriage-market relevant social grouping. This is suggested by the finding of McCrary and Royer (2006) who use date of birth relative to school entry cutoff as instrument for educational attainment for mothers in Texas and California, and find that mothers born after the school entry cutoff date have younger partners.
} 
at the beginning of the term in which they turn 5. The system that is becoming increasingly popular over time is based on a single-entry-point, which implies that all children start school in September of the academic year in which they turn 5, regardless of age. Nearly half of the children born between 1997 and 1999 started school in an LEA where this single-entry-point system was in operation (see Crawford et al. 2007)

\section{School Leaving Policy}

The British government has raised the minimum school leaving age several times since the introduction of compulsory education in 1870. The main motivations given have been focused on generating more skilled labour by providing additional time for students to gain skills and qualifications. The current school leaving age of 16 has been in force since September 1973, as a result of the Raising of School Leaving Age (RoSLA) Order of 1972. This built on the previous RoSLA from 14 to 15 which occurred in April 1947, following the 1944 "Butler" Education Act.

Unlike in the US, children in the UK are generally not deemed to have attained the age of compulsory schooling, and therefore allowed to leave school, on the exact date in which they themselves attain the age of 16. Since the Education Act of 1962 and up until 1997, the minimum school leaving age arrangements were as follows:

- A child whose sixteenth birthday fell in the period September 1 to January 31 inclusive, was allowed to leave compulsory schooling at the end of the Spring term (which ends just before Easter).

- A child whose sixteenth birthday fell in the period February 1 to August 31, was allowed to leave on the Friday before the last Monday in May 9

From 1998 onward, a new single school leaving date was set as the last Friday in June in the school year in which the child reaches the age of 16, as a result of the 1996 Education Act. However, since our empirical analysis will focus on individuals who attained the minimum school

\footnotetext{
${ }^{9}$ The justification for dual exit dates seems to have been the belief that a common exit date, with entire cohorts leaving school at the same time, would negatively affect the functioning of the labour market. [REF]
} 
leaving age of 16 during the 1970s and the 1980s, the earlier school leaving arrangements will be the relevant ones for our purposes.

The combination of the school entry policy and the school leaving policy implied two distinct discontinuities in required length of schooling with respect to date of birth. First, a discontinuity obtained at the cutoff dates between academic cohorts, i.e. at the August-September threshold. While August-born children were forced to stay until the end of the school year, September-born children were allowed to leave at Easter. Since those born after the threshold date have shorter required schooling, this discontinuity has strong similarities to the discontinuities generated by school entry policy in the US as used by Angrist and Krueger (1991) and many after them. Second, a discontinuity obtains also at the winter cutoff date for being allowed to leave at Easter, i.e. at the January-February threshold. While January-born children were allowed to leave at Easter, February-born children were forced to stay until the end of the school year. Although the two discontinuities at a first glance appear to be "flipsides" of each other there is nevertheless an important difference: while the first discontinuity obtained between academic cohorts, the second discontinuity obtained within academic cohorts. The fact the first discontinuity obtains between academic cohorts implies that the required length of schooling is not the only difference between individuals born on opposite sides of the threshold. Those born after the threshold would start school later than those born before it and would belong to a one-year later academic cohort: hence those born after the threshold would have a higher absolute age at school start and also a higher age relative to their academic cohort peers. In contrast, for the second discontinuity, by virtue of January and February born children belonging to the same academic cohort, and generally starting school at the same time, neither age effect would have obtained. For this reason the second discontinuity has stronger appeal as a pure required education effect and will be the one focused on in this paper.

The significance of the discontinuity is, however, not only that it implies a nominal difference of two to three months (one term) of required schooling. More importantly, it interacts with the qualification system in England and Wales under which students aged 16 sit crucial intermediatelevel examinations at the end of the summer term. 


\section{Exams Sat at 16}

At the end of five years of compulsory secondary education, students in England and Wales take exams in a range of subjects. Historically, different types of schools entered their pupils for different examinations at age 16. Students who were academically inclined and attended "grammar schools" would take General Certificate of Education Ordinary Levels ("GCE O-level) examinations. In contrast, less academically oriented students attending "secondary modern schools" could take the Certificate of Secondary Education (CSE) examinations at 16 before leaving school. Less demanding than GCE O-level, results in the CSE exams were nevertheless graded on the same scale, with the top CSE grade, grade 1, being equivalent to a simple pass at GCE O-level.

The introduction in 1988 of the General Certificate of Secondary Education (GCSE), which superseded the O-level and CSE exams, marked a turning point in UK educational system. The GCSE is a single subject exam and students usually take up to ten (there is no upper limit) GCSE exams in different subjects. Students are given a letter score of A-G where A is the top grade. Although grades A-G are all officially pass grades, only grades A to C are generally regarded as equivalent to the "pass" grades in the previous O-level system.

Our empirical analysis will focus on the academic cohorts that faced the previously existing O-level/CSE system for which we observe a significant difference in academic attainment by date of birth relative to the January-February threshold. With the introduction of the more inclusive GSCE system, the fraction of individuals holding some academic qualification increased and the date of birth effect vanishes. Moreover, we will focus on those cohorts that faced the minimum school leaving age of 16 . Under the previous age of 15 , whether or not a student could leave at Easter was effectively inconsequential since leaving at the earliest possible date meant leaving school a year prior to the qualifications-generating examinations sat at age 16 ${ }^{10}$ Hence in our analysis below, the main focus will be on individuals born after September 1957 (and hence born

\footnotetext{
${ }^{10}$ Even when the minimum school leaving age was 16 , students leaving at Easter had the option of returning for exams and evidence suggests that a substantial fraction of students did so (Del Bono and Galindo-Rueda, 2006).
} 
late enough to face the current age 16 minimum school leaving age) but born before August 1971 (and hence born early enough to face the previous O-level/CSE examination system).

\section{Data and Sample}

The data we will use comes from the UK Labour Force Survey (LFS) which is the largest regular household survey in the United Kingdom and is intended to be representative of the whole UK population. The sample design currently consists of about 60,000 responding households every quarter, representing about $0.2 \%$ of the British population. Prior to 1992 LFS data is available on an annual basis, based on interviews taking place in the Spring (March-May). However, since 1992 LFS data is available on a quarterly basis ${ }^{11}$ We pool data from the survey years 1984 to 2006. The LFS surveys prior to 1983 are not comparable with later surveys because of inconsistencies in measurement, definitions and coverage, while 2006 is the last year for which month of birth has been made publicly available.

The LFS is suitable for our purposes due to its size and since it contains the basic information needed for our application: year and month of birth, ethnicity, educational attainment, marital status, and employment status.

The basic sample criteria we use are as follows. We select women born and currently living in England or Wales who are aged 18 or above at the time of interview ${ }^{12}$ As noted above, in

\footnotetext{
${ }^{11}$ Indeed, with the restructuring of the LFS in 1992, the survey was transformed into a "rotating panel". Each quarter's LFS sample is made up of five "waves". Each wave is interviewed in five successive quarters, such that in any one quarter, one wave will be receiving their first interview, one wave their second, and so on, with one wave receiving their fifth and final interview. However, since we are not interested in time varying characteristics or outcomes, we will not be making use of the panel structure of the LFS. Instead we will only be using information provided by individuals in their first interview.

${ }^{12}$ Prior to 2001 there is no information about in which country of the UK individuals are born. We then keep those born in the UK and currently living in England and Wales. Hence for earlier survey years there is some unavoidable degree of noise due to migration from Scotland and Northern Ireland. We do not impose any explicit upper limit on age. However, per construction, the oldest individual that will be included in the data will be someone born in the Autumn of 1957 and observed in the Autumn of 2006. Hence no one in the main sample
} 
our main analysis we further restrict our attention to individuals belonging to a certain set of academic cohort, in particular, we include individuals born between September 1957 and August 1971.

For each individual we have information on year and month of birth. Since we also know the year and month of interview we know the individual's age in months when surveyed. For marital status we will consider exclusively whether or not the individuals is currently married - the survey does not allow us to determine any details of the individuals' marital histories 13 We observe the current employment status of each individual and label an individual as being "economically active" if currently employed or self-employed.

With regards to educational attainment we have several pieces of information. Fundamentally the individuals report the age at which they left continuous full time education and what qualifications they hold. The standard measure of age when leaving full time education is not the most useful for the current purposes as will be made clear below. Instead we focus on formal qualifications held by the individuals. In particular, we will focus on academic qualifications. Indeed, for most of the analysis we will simply consider whether an individual holds any academic qualification. There are several reasons for doing so, generally having to do with timing and exams. First, individuals tend to obtain academic qualifications in a certain sequence, implying that higher levels of qualifications are obtained at higher ages. Whether or not an individual will ever obtain any academic qualification is typically determined by the exams sat at age 16 . Hence when we consider a given academic cohort, as we observe them in across time, they will tend to improve their composition of academic qualifications over time as they age. However, the fraction of any given cohort that holds some academic qualification is effectively constant across time. Second, while we also have information on vocational qualifications, such qualifications will be aged above 50 .

\footnotetext{
${ }^{13}$ We focus on whether an individual is currently legally married. Those that are not married hence include both never married and divorced (and legally separated). Moreover, those currently not married also include cohabitants. Unfortunately, due to changes in the underlying survey question, the data does not allow us to identify divorced individuals and cohabitants consistently across time.
} 
are more frequently obtained at various stages in the individuals' lives. As a result, when we consider the fraction of any given academic cohort that holds some qualification (academic or vocational) we observe this fraction to be increasing over time as the cohort ages. Such apparent "skill upgrading" would cause a host of problems for the analysis, including problems relating to interpretation; e.g. we would be less certain that skill acquisition comes before marriage. Third, and fundamentally, the O-level and CSE examinations taken at the age of 16, i.e. at the end of the academic year in which those born September to January would have the option to leave at Easter, each provide an academic qualification. As a result we observe larger gaps in the rate of holding some academic qualification than gaps in the rate of holding any (academic or vocational) qualification.

Mostly for descriptive purposes we classify the individuals by their highest academic qualification into five "levels" where (i) "Level 1" denotes a CSE qualification, (ii) "Level 2" denotes an O-level qualification, (iii) "Level 3" denotes an A-level qualification (an "Advanced Level" examinations taken at age 18 relevant for entry into higher education), (iv) "Level 4" denotes a first degree (or equivalent), and (v) "Level 5" denotes a higher degree (at postgraduate level).

Table 1 provides summary statistics broken down by current marital status. As expected, married women are, on average, older than unmarried women. Married and unmarried women have very similar economic activity rates in the current sample. Married women more frequently hold some academic qualification. The table also shows that there are relatively few ethnic minority women in our sample, largely due to our focus on individuals born in the UK. Hence we will not be able to separately consider ethnic minorities in the analysis below. Among the husbands to the married women in the sample, 68 percent hold some academic qualification and 90 percent are economically active. As a short-hand we refer to individuals born in the months February-August as "required to stay on". This group constitute 59 percent of the sample.

\section{Month of Birth and Family Background}

In theoretical analysis above it was assumed that the instrument $z_{i}$ was uncorrelated with the individual's characteristics $\alpha_{i}$. In the empirical analysis below the instrument used is based on 
month of birth, with $z_{i}$ "switched on" for those born in months that would make them required to stay on,

$$
z_{i}=\left\{\begin{array}{ll}
1 & \text { if } M o B_{i} \in\{2, \ldots, 8\} \\
0 & \text { else }
\end{array} .\right.
$$

This short section explores briefly whether individuals' characteristics are unrelated to their month of birth ${ }^{14}$ It is important to note that even if there is a systematic relationship between month of birth and some personal characteristic, identification can still be secured in two cases. The first case is when the characteristic is observed and hence can be directly controlled for. The second case is when the distribution of the individual characteristic is continuous with respect to date of birth at the relevant threshold date. In this latter case, individuals on either side of, but close to, the threshold are effectively identical in all other respect other than with respect to the instrument and the analysis above holds for individuals close to the threshold $\sqrt{15}$ This motivates why, in the analysis below, we have carefully examined the sensitivity of our estimates with respect to window size.

We can use the LFS to explore whether there is any systematic relationship between family background and month of birth by using the fact that the LFS obtains information not only about the adults in the survey households but also about the children. Hence we can select a sample of children and relate their months of birth to family characteristics. To this end we use the LFS annual surveys 1984 to 1991 for which all interviews take place in the spring. We select all children up to and including the 1974-75 academic cohort who are observed in the academic year in which they turn 14,15 or $16{ }^{16}$ In order to obtain a larger sample size we include both girls and boys. This gives a sample of 40,636 children. For this sample of children we measure

\footnotetext{
${ }^{14}$ The use of quarter of birth as an instrument for educational attainment in the US context has recently been criticized by Buckles and Hungerman (2008). They highlight e.g. that women giving birth in the winter months are more often teenagers, less frequently married, less frequently white, less educated and younger.

${ }^{15}$ Formally, unbiasedness obtains in the limit as the window size if reduced to zero. See e.g. Hahn, Todd and van der Klaauw (2001) for a theoretical discussion and McCrary and Royer (2006) for an application.

${ }^{16}$ The selection rule applied ensures that we capture complete academic cohorts. The earliest academic cohort included in this sample of children is the 1967-68 academic cohort.
} 
the parents' academic qualifications, economic activity and age at birth (measured in month) 17 For the child him/herself we also consider ethnicity.

Figure 1 shows averages of these variable by month of birth of the child. Fathers are about 30 months older than the mothers, and there is no apparent relationship between parents' age and month of birth of the child. Similarly, the economic activity rate for fathers is about 20 percentage points higher than that for mothers, and there is no apparent relationship to the child's month of birth. Turning to academic qualifications, fathers to children born in the spring appear to slightly more often hold an academic qualification at the degree level or above (Ac. Qual. 4-5). Similarly, mothers to spring-born children more often hold a low-level academic qualification (Ac. Qual. 1-2). Finally, ethnicity shows no particular relation to month of birth.

In so far as there is any family background characteristic that is related to month of birth, this would cause problems for our analysis particularly if that relationship was discontinuous at the January-February threshold. In order to consider this possibility, we also perform a regression analysis where each family background variable is regressed on $z_{i}$ (defined as in (7)) and on a full set of academic cohort- and survey-year dummies. Moreover, each regression is carried out for five "window-sizes" around the January-February threshold, starting from a wide window of five months on either side of the threshold and going down to a single month on either side. In line with Figure 1, these regressions, presented in Table 2, indicate no discontinuities in parents' age and economic activity and in ethnicity. The regressions show that mothers to spring-born children are more likely to hold a level 1-2 academic qualification; however, since the difference disappears as the window-size reduces, there is no evidence of any discontinuity at the threshold point. The only characteristic for which there are significant differences by month of birth, and which does not diminish as the window-size is reduced, is fathers holding an academic qualification at degree level or above (level 4-5). Since, in the analysis below, we cannot control for parents' academic qualification, we need to highlight this as a potential caveat 18

\footnotetext{
${ }^{17}$ It should be noted that only parents living in the same household are observed and that parents may include step-parents.

${ }^{18}$ Due to this concern we have also explored an alternative data set - the Youth Cohort Surveys - which allows
} 


\section{Results}

We present our result in three subsections. In the first subsection we consider how academic attainment varies with month of birth. We show that those who were required to stay on are significantly more likely to hold some academic qualification. In particular, the gap in attainment obtains on the margin between holding no academic qualification and holding some low level (level 1 or 2) qualification. We show that the gap in academic attainment diminishes in later cohorts.

There are two threshold points in the academic year. The first is the August-September threshold. Those born after this threshold (i.e. in September onwards) would belong to the following academic cohort and would generally have to wait to start school relative to those born before the threshold. Moreover, those born after the this threshold would not have been required to stay on. The second is the January-February threshold. Individuals on either side of this threshold would belong to the same academic cohort, but would differ in the requirement to stay on.

We show that academic attainment changes monotonically at the January-February threshold: those born after the threshold date (and hence would have been required to stay on) have uniformly higher academic attainment than those individuals born before the threshold date. In contrast, academic attainment does not change monotonically at the August-September threshold: while those born before this threshold are more likely to hold some low level qualification, those born after the threshold are more likely to hold some higher level qualification. Due to this lack of monotonicity at the August-September threshold, we henceforth focus on the January-February threshold.

In the second subsection we look at marital status. After verifying that individuals with academic qualifications are, at higher ages, more likely to be married, we consider in detail how

us to explore the same relationship for the same academic cohorts and with a similar sample size. In the YCS we find evidence of a smaller gap in the rate of fathers' holding a degree, which moreover disappears as the window size is reduced. Details of this analysis is available on request from the authors. 
the probability of being married varies with month of birth. We find little evidence of any such variation. In particular, we cannot find any evidence that those who were required to stay on in school are either more or less likely to be married. Hence we conclude that there was no causal effect of holding an academic qualification on the probability of being currently married.

In the final subsection we restrict the sample to married women and look at the characteristics of their spouses. After verifying that holding some academic qualification is strongly positively correlated with the spouse holding some academic qualification and being economically active, we consider whether the spouse's characteristics vary with the woman's month of birth. Our findings suggest that women who were required to stay on more frequently are married to husbands who hold some academic qualification and who are economically active. Hence our IV estimates suggest a causal effect of the woman's academic qualification on the properties of her spouse.

\section{Month of Birth and Academic Attainment}

We begin with an analysis of the relationship between month of birth and academic attainment. Figure 2 plots the distribution of highest academic qualification by month of birth. There is a marked increase in the fraction holding a level 1 academic qualification at the January-February threshold, along with a corresponding decrease in the fraction holding no academic qualification. The figure also suggests that having been required to stay on is potentially associated with a slight increase in the probability of holding a level 2 academic qualification. For higher qualifications there is no evidence of any discontinuity at the January-February threshold date.

A key requirement for the instrumental variable approach to generate interpretatable results is that the impact of the instrumental variable should have a monotonic impact on the endogenous variable. From Figure 2 it is clear that having been required to stay on increased the probability of the individual holding some low level of qualification. However, we also want to compare the cumulative distribution functions of academic attainment for those born before and after the threshold in order to verify that there is no academic attainment level at or above which those required to stay on are relatively infrequent. In order to do this we report the 
results from a set of estimated linear probability models where, for each academic qualification level $j$, we regress a dummy for the individual holding that level of qualification or above on a dummy for having been required to stay on, on a set of academic cohort dummies, on a set of survey year dummies, on a set of ethnicity dummies, and on age-in-months in linear, square and cubic form 19 Only if all estimated coefficients are positive can we argue that those born after the January-February threshold are unambiguously more academically qualified. Moreover, in order to explore the sensitivity of the estimates, we vary the "window-size" from four months on either side of the threshold (i.e. including everyone born September through June) down to one month on either side (i.e. only including those born in January and February).

Table 3 gives the coefficient on having been required to stay on in each regression. The table confirms that the main effect of having been required to stay on is on the "no qualification" versus "some qualification" margin: the effect of being born after the threshold on the probability of holding at least a level 1 academic qualification is economically significant, around three and a half percentage point and relatively stable with respect to the window size. The regressions suggest that those who were required to stay on are also slightly more likely to hold level 2 qualifications (O-level or CSE grade 1) and level 4 qualifications (first degree or equivalent). While level 1 and level 2 qualifications would be obtained through exams sat at the age of 16, the finding of a higher rate of holding level 4 qualifications for women born after the threshold date suggests that some women who were affected by the requirement to remain in school for one extra term may in fact have responded by staying on even longer. We return to this issue below. Of key importance for our purposes, the complete absence of any statistically significant negative coefficients in Table 3 suggests an unambiguously positive impact of being born after the threshold date on academic attainment.

To contrast this, we perform a similar analysis of academic attainment by month of birth around the August-September threshold. Figure 3 shows the coefficients on having been required to stay on. The left panel uses a set of windows around the January-February threshold (and

\footnotetext{
${ }^{19}$ Note that even two individuals born in the same academic cohort and interviewed in the same calendar year can differ in age in month due to differences in month of birth and in month of interview.
} 
hence displays a subset of the coefficients from Table 3). The right panel shows corresponding estimated coefficients on having been required to stay on using a set of windows around the August-September threshold. Note that in these latter regressions, someone required to stay, while born in the same calendar year, belongs to a one-year earlier academic cohort than someone not required to stay on ${ }^{20}$ The figure shows that while having been required to stay on monotonically increases academic attainment at the January-February threshold, the same is not true at the August-September threshold. Individuals born before the August-September threshold (who were required to stay on) are indeed more likely to hold some academic qualification. However, they are less likely to hold qualifications at levels 2 to 4 . This feature likely reflects the type of relative-age-at-school-start effect highlighted by Crawford et al. (2007) whereby those who are oldest within their academic cohort perform better.

So far we have not considered whether the effect of having been required to stay on was the same in all academic cohorts. To consider this, Figure 4 plots the fraction of individuals in each academic cohort, separated into those born before and those born after the threshold, who hold some academic qualification. For the purpose of this particular figure we have also extended the sample to include the five academic cohorts before our main sample and seven cohorts following. The five academic cohorts before the current main sample were not affected by the 1973 raising of the school leaving age (RoSLA) and hence faced a minimum school leaving age of 15 . This meant that everyone had the option of leaving school before the exams at age 16. As a result, the fraction holding some academic qualification is markedly lower and, specifically, there are no noticeable differences between those born before and after the January-February thresholds. For the main sample cohorts, we observe that the rate of holding some academic qualification trends upwards. Moreover, Figure 4 illustrates how the gap in attainment between those required to stay on and those not was particularly large in the early years following the RoSLA. Gradually the gap then reduced. Our main sample stops with the replacement of the CSE and O-level qualifications with the current GCSE (General Certificate of Secondary Education) system: the

\footnotetext{
${ }^{20}$ In the analysis of the August-September threshold we control for birth year cohort rather than for academic cohort.
} 
final students to sit the former O-Level/CSE examinations were those of May-June 1987. The figure shows that only in the first year of the new system was there any noticeable gap in the rate of holding some academic qualification.

Above we found that the main impact of the requirement to stay on academic attainment was to move individuals from the no-qualifications group to the level 1 qualifications group. Here we illustrate this in different way by looking at the age at which the individuals left fulltime education. Consider the hypothesis that the only effect of the school-leaving policy was to induce some people born after the January-February threshold date to stay on for exactly one extra term. Then some January-born children would leave at Easter while the corresponding individuals born in February would leave a few months later, in the summer. Since both groups leave education in the same calendar year and after their birthdays, both groups would have the same age stated in years when leaving education. Hence, under the hypothesis, there should be no differences in the distributions of age at leaving full time education between those required to stay on and those not. We partition age when leaving full time education into four categories: 16 or below, 17, 18, and 19 or above. Table 4 presents estimates of the effect of having been required to stay on on the probability of leaving full-time education at these various ages, based on regressions that contain the standard set of controls. The noticeable feature of Table 4 is the near complete absence of any effect. The only statistically significant effect obtains at age 18, with those who were required to stay on being possibly half a percentage point more likely to leave at age 18. This is consistent with the observation above that those who were required to stay on appear to slightly more frequently hold intermediate level academic qualifications.

To sum up, the requirement to stay in school for one extra term at the compulsory age of 16 imposed on those born after the January-February threshold had an unambiguously positive impact on their academic attainment, with the main effect being an increase in the rate of holding a level 1 academic qualification and a corresponding decrease in the rate of holding no academic qualification. 


\section{Marital Status}

We now consider marital status. We start by noting that individuals who invest in education have lower frequencies of being married at lower ages but higher frequencies of being married at higher ages. This is highlighted in Figure 5 which shows the fraction of individuals who are currently married by level of academic attainment relative to individuals who hold no academic qualification ${ }^{21}$ The figure shows how, up until the age of around 28-30, those who obtain a level 4-5 academic qualification (corresponding to university studies) are markedly less frequently married than those with no qualifications. A similar, but smaller, effect is evident for those who obtain a level 2-3 academic qualification. After the age of 30, however, those with no academic qualification are the least likely to be married out of all attainment groups, with the gap in marriage frequency being around 10 percentage point relative to every other level of attainment. Hence there is a strong association between academic attainment and the probability of being married. However, it is less clear whether that association reflects a causal effect rather than pure selection. To consider this we examine how the fraction currently married varies with month of birth.

The upper part of Figure 6 shows the fraction currently married at each age, for individuals born in the months November-January (and hence not required to stay on) and FebruaryApril (and hence required to stay on) respectively, controlling for academic cohort, survey year, ethnicity, and for differences in age in months. Due to the scale it is difficult to visually detect any differences. For that reason, the lower part of Figure 6 shows the estimated difference by age. The overall difference (indicated by the hatched line) is actually negative, but very small and not statistically significant. Hence, we cannot find any evidence to suggest that those who were required to stay on are more likely to be married.

We can also consider in some more detail how the fraction currently married varies with month of birth. Since we only observe a positive association between (a low level) academic

\footnotetext{
${ }^{21}$ Specifically, the figure illustrates the coefficients on the various levels of academic attainment from regressions, one for each age, which also includes controls for academic cohort, survey year, and ethnicity.
} 
qualifications and marriage for individuals above their early 20s we focus here on individuals aged 23 or above. To this end we regress a dummy for being married on a set of month of birth dummies (leaving out February as reference group), along with a full set of academic cohort dummies, survey year dummies, ethnicity dummies, and age in months (in linear, square and cubic form). The left panel of Figure 7 plots the frequency of being currently married by month of birth relative to February (i.e. the estimated coefficient on each month of birth in the regression). The figure shows that the probability of being married declines slightly with month of birth within the academic year. This finding is somewhat surprising if one believes that individuals' demographic life events depend not only on their absolute age, but also on their "social age" defined by their academic cohort (Skirbekk, Kohler and Prskawetz, 2004). Nevertheless, the most important aspect is that there is no suggestion of any "discontinuity" at the January-February threshold date.

In order to explore in further detail whether there is any difference in marriage frequency we estimate a set of linear probability models where the dummy for being married is regressed on a dummy for having been required to stay on along with the same controls as above, but with varying window sizes around the threshold date. Focusing again on those aged 23 or above, the right panel of Figure 7 shows the coefficient on having been required to stay on (and the 95 percent confidence interval) as the window size is gradually reduced from five months on either side of the threshold down to only one month on either side. The figure shows that the difference in the fraction currently married is effectively zero for all window sizes except the very smallest. Hence, from this analysis, we conclude that there is no indication that the probability of being currently married changes discontinuously with month of birth at the threshold point.

Consider then using the dummy for having been required to stay on as an instrumental variable for estimating the effect of holding an academic qualification on the probability of being married. Focusing again on individuals aged 23 or above, Table 5 presents the estimated effect of holding some academic qualification on the probability of currently being married as the window size is gradually reduced. The OLS estimates consistently show a nine percentage point increase in the probability of being currently married. The IV estimates are effectively zero (or 
negative) for all window sizes except the smallest one (which is also highly imprecise). Hence we conclude that for women there is no evidence of any causal effect of holding an academic qualification on the probability of being currently married ${ }^{22}$

\section{Spousal Characteristics}

So far we have found that those who, due to being born later in the academic year, were required to stay on for an extra term more frequently obtained some academic qualification. In contrast, we could not find any difference in the probability of being currently married between those required to stay on and those not. From this latter observation, we concluded that holding an academic qualification had no impact on the marriage probability for the group of individuals whose educational attainment strictly depended on whether they were required to stay on or not.

We now proceed to study the characteristics of the spouses of the married women in the sample. We consider two partner characteristics: (i) whether the partner holds any academic qualification, and (ii) whether or not the partner is economically active. In doing so we rely on the fact that our finding of no difference in marriage frequency between those required to stay on and those not is consistent with the identifying assumption that the marriage probabilities of all "compliers" do not depend on whether they hold any academic qualification or not (see Section II .

As expected there is a strong positive association between a woman's academic qualification and that of her spouse. Table 6 shows the OLS estimated effect of holding an academic qualification at various levels on the probability of the spouse holding some academic qualification. Women with academic qualifications are much more likely to be married to husbands who also have some academic qualification 23 Indeed, while the probability of being married to a part-

\footnotetext{
${ }^{22}$ We have also performed a similar analysis using only individuals aged 18 to 22 . However, unsurprisingly, for this age group the estimates are too imprecise to allow any meaningful conclusions to be drawn.

${ }^{23}$ More generally it is also true that there is marital sorting by qualification level. E.g. for any academic qualification level $j$ (including no qualification) a woman with qualification level $j$ is more likely to be married to
} 
ner with some academic qualification increases with the individual's own qualification level, the largest difference obtains between women with no qualification and a level 1 qualification. Table 6 also shows the OLS estimated effect of a woman holding various levels of academic qualifications on the probability of her husband being economically active. Here the main difference is precisely between women with no academic qualification and some academic qualification: conditional on holding some academic qualification, the partner's economic activity rate varies little with the particular qualification level held by the woman.

Consider then how spouse characteristics vary with the individual's month of birth. Adopting the same regression approach as above (and the same controls), the left panel of Figure 8 shows how the probability of a woman being married to husband who holds some academic qualification differs by her month of birth relative to the omitted February reference group. While somewhat noisy, the figure suggests that women born in the first five months of the academic year are less likely to be married to husbands with some academic qualification. The right panel of Figure 8 shows the corresponding results for the husbands' economic activity rates. This figure shows a clear tendency for women born in the first five months of the academic year to be married to economically inactive husbands.

Figure 9 looks more closely at the difference in the properties of the husbands of those women who were required to stay and those that were not. Following the approach from above, the figure illustrates the estimated coefficients on a dummy for having been required to stay on (using regressions with the same controls as above), and with varying window sizes. The left panel shows that women born after the January-February threshold are more likely to have husbands who hold some academic qualification than are married women born before the threshold. Moreover, the difference is fairly stable with respect to the window size and is statistically significant for all window sizes except the smallest one. The right panel shows that the same is true also for the economic activity rate of the husbands: those women who were required to stay on are more frequently married to working husbands. Moreover, the gap is stable with respect to the window size and is statistically significant at every window size except the smallest one.

a qualification level $j$ male than any other women, and vice versa. 
These findings map into corresponding IV estimates. Table 7 presents the estimated effects using OLS and using IV (and for varying window sizes). For the partner holding some academic qualification, the IV estimates are always positive, reasonably stable with respect to window size, and statistically significant at all window sizes except the smallest one. The IV estimates are smaller than the OLS estimates, but are more similar to the OLS estimate of specifically holding a level 1 academic qualification (See Table 6). Similarly, for the partner being economically active, the IV estimates are always positive, stable with respect to window size, and statistically significant at all window sizes except the smallest one. Moreover, the IV estimates are very similar to the OLS estimates ${ }^{24}$

The evidence thus suggests that the requirement for some women to stay on for an extra term at the compulsory school leaving age not only significantly increased their rate of holding some academic qualification, but also increased the rate at which they married husbands holding some academic qualification and who (years later) are more frequently economically active. Indeed, the IV estimates which purport to measure the causal effect of a woman holding an academic qualification on the properties of her husband are very similar to the OLS estimates. This is in itself somewhat surprising in that it suggests that most of the positive association we observe between women's holding an academic qualification and the academic qualification and economic activity rate of their husbands operate through causal channels. As the theoretical exposition above made clear, an otherwise very plausible non-causal channel would be that individuals who meet naturally tend to have correlated characteristics.

\section{Robustness Analysis}

The main finding so far has been that women born in February or later in the academic year (i) more frequently hold some academic qualification, and (ii) are more frequently married to

\footnotetext{
${ }^{24}$ For comparison we have also estimated the effect of holding an academic qualification on the women's own economic activity rate. While the IV point estimates are of the same order of magnitude as those for the partner's economic activity rate, they are estimated less precisely. Details of these regressions are available on request from the authors.
} 
husbands who hold some academic qualification and who are economically active. From this it was argued that the holding of an academic qualification affected the properties of the women's subsequent husbands.

In Figure 4 it was shown that the gap in the qualification rate only existed in academic cohorts from 1957 to 1970 , i.e. the academic cohorts born late enough to face the minimum school leaving age of 16 but early enough to sit exams before the introduction of the GCSEs. A natural robustness test is then to check whether month of birth relative to the January-February threshold only matters for the 1957 to 1970 academic cohorts also in terms of marital outcomes 25 To this end we use an extended sample of married women which includes all academic cohorts from 1952 through to 1975 . We regress each spouse characteristic on the dummy for having been required to stay on (along with survey year dummies, academic cohort dummies, ethnicity dummies, and age in month in linear and square form), but we allow the effect of having been required to stay on to be different in the "pre-period" (the five academic cohorts 1952-1956), the "main period" (the 1957-1970 academic cohorts), and the "post-period" (the five academic cohorts 1971-1975). As above, we do this for varying window sizes.

The results are provided in Table 8. Looking first at spouse qualification rate, the top part of Table 8 shows that, in the main period, having been required to stay on is associated with about a one percentage point higher probability of being married to a partner who holds some academic qualification. Moreover, this estimate is not sensitive to the window size and is statistically significant for all window sizes except the smallest. In contrast, in the pre-period, the estimates are close to zero and never statistically significant, while in the post period the estimates are generally negative (but not very precise). Hence the positive relation between having been required to stay on and spouse qualification rate only appear to exist in the main period, which is also the only period in which having been required to stay on is associated with a higher own qualification rate.

Turning to spouse economic activity rate, for the main period, having been required to stay on

\footnotetext{
${ }^{25}$ It should be noted however that this is not an ideal test in the sense that the 1957 to 1970 academic cohorts were not the only ones to face the Easter-exit rule - the same rule also affected earlier and later cohorts.
} 
is associated with $0.6-0.8$ percentage point higher probability of being married to an economically active husband, with the estimates being stable with respect to window size and statistically significant for all window sizes except the smallest. However, in this case the estimates tend also to be positive in the pre- and post-periods. Nevertheless, the estimates in these periods slightly smaller, not statistically significant, and are effectively zero for the smallest window size. Hence, while slightly less conclusive, the results suggest that the main period is the only period for which having been required to stay on is robustly associated with a higher probability of being married to an economically active husband.

\section{Conclusions}

In this paper we have exploited a particular historical feature of the schooling laws in England and Wales which allowed those individuals born in the first five months of the academic year to leave education at Easter of the year in which they reached the minimum school leaving age, one term ahead of their class mates born in the remaining seven months of the academic year. For the 14 academic cohorts that we focus on, the interaction of this feature with the exam system implied a discontinuity in the rate of holding some academic qualification with respect to month of birth, with a woman born in February or later being more than 3.5 percentage points more likely to hold some academic qualification than a woman born earlier in the academic year.

While there is a strong positive association between holding an academic qualification (at any level) and being currently married for women beyond their mid-20s, there is no suggestion of any difference in the rate of being married between those women who were required to stay on for the extra term and those who were not. Hence our findings strongly suggest that holding an academic qualification had no long-run effect on the probability of being married for the population that we study. The absence of an effect on the probability of being married, however, does not imply that holding an academic qualification was necessarily marriage-irrelevant. Indeed, those who, due to their month of birth, were required to stay on for the extra term were found to be married to husbands who more frequently hold some academic qualification and who more frequently are 
economically active. In fact, our results suggest that most of the observed positive association between a woman's holding of an academic qualification and her husband's characteristics can be given a causal interpretation.

A causal effect of a woman's academic qualification on the characteristics of her spouse can obtain fundamentally through two distinct channels. First, a qualification can make her more "attractive" in the marriage market, leading to a different marriage propensity at any given match with a potential partner: with a qualification she may not be turned down by someone who would have done so had she been unqualified, and she herself may become more inclined to reject less qualified men. Second, it may be that investing in education leads a woman to meet a different selection of potential partners. In this context it is interesting to note that those who were required to stay on would typically not have had to change school or even class in order to comply. Moreover, very few of those required to stay on for an extra term appear to have responded by staying on even longer and obtain some higher level of qualification. This suggest that the staying on requirement is unlikely to have affected the selection of potential partners met directly through school.

\section{References}

Angrist, J. D. \& Krueger., A. B. (1991), 'Does compulsory school attendance affect schooling and earnings?', Quarterly Journal of Economics 106, 979-1014.

Angrist, J., Imbens, G. \& Rubin, D. (1996), 'Identification of causal effects using instrumental variables', Journal of the American Statistical Association 91, 444-455.

Becker, G. S. (1973), 'A theory of marriage, part', Journal of Political Economy 81, 813-846.

Becker, G. S. (1991), A Treatise on the Family, Harvard University Press, Cambridge, Mass. Enlarged Edition.

Behrman, J. R. \& Rosenzweig, M. R. (2002), 'Does increasing womens schooling raise the schooling of the next generation?', American Economic Review 92, 323-334. 
Breierova, L. \& Duflo, E. (2004), 'The impact of education on fertility and child mortality: Do fathers really matter less than mothers?'. NBER Working Paper Nr.10513.

Buckles, K. \& Hungerman, D. M. (2008), 'Season of birth and later outcomes: Old questions, new answers'. Mimeo. University of Notre Dame.

Burgess, E. W. \& Wallin, P. (1943), 'Homogamy in social characteristics', American Journal of Sociology 49, 109-124.

Chiappori, P.-A., Iyigun, M. \& Weiss, Y. (2009), 'Investment in schooling and the marriage market', American Economic Review 99, 1689-1713.

Crawford, C., Dearden, L. \& Meghir, C. (2007), 'When you are born matters: The impact of date of birth on child cognitive outcomes in England'. Centre for the Economics of Education.

Del Bono, E. \& Galindo-Rueda, F. (2006), 'The long term impacts of compulsory schooling: Evidence from a natural experiment in school leaving dates'. ISER Working Paper 200644. University of Essex.

Duflo, E., Dupas, P. \& Kremer, M. (2010), 'Education and fertility: Experimental evidence from Kenya'. Mimeo.

Fort, M. (2007), 'Just a matter of time: Empirical evidence on the causal effect of education on fertility in Italy'. Mimeo.

Goldin, C. (1992), 'The meaning of college in the lives of american women: The past one-hundred years.'. National Bureau of Economic Research, Cambridge, MA. Working Paper Nr. 4099.

Hahn, J., Todd, P. \& van der Klaauw, W. (2001), 'Identification and estimation of treatment effects with a regression discontinuity design', Econometrica 69, 201-209.

Hunt, T. C. (1940), 'Occupational status and marriage selection', American Sociological Review 5, 495-505. 
Imbens, G. \& Angrist, J. (1994), 'Identification and estimation of local average treatment effects', Econometrica 62, 467-475.

Kirdar, M. G., Tayfur, M. D. \& Koç, I. (2010), 'The impact of schooling on the timing of marriage and fertility: Evidence from a change in compulsory schooling law'. MPRA Paper Number 13410.

Lefgren, L. \& McIntyre, F. (2006), 'The relationship between womens education and marriage outcomes', Journal of Labor Economics 24, 787-830.

Lommerud, K. E. \& Konrad, K. (2008), 'Love and taxes - and matching institutions'. C.E.P.R. Discussion Paper No. 6703.

McCrary, J. \& Royer, H. (2006), 'The effect of female education on fertility and infant health: Evidence from school entry policies using exact date of birth'. NBER Working Paper No. 12329.

Oreopoulos, P. \& Salvanes, K. G. (2009), 'How large are returns to schooling? hint: Money isn’t everything'. NBER Working Paper No. 15339.

Peters, M. \& Siow, A. (2002), 'Competing premarital investments', Journal of Political Economy 110, 592-608.

Rockwell, R. (1976), 'Historical trends and variations in educational homogamy', Journal of Marriage and the Family 38, 83-96.

Skirbekk, V., Kohler, H. P. \& Prskawetz, A. (2004), 'Birth month, school graduation, and the timing of births and marriages', Demography 41, 547-568. 
Table 1: Descriptive Statistics

\begin{tabular}{|c|c|c|c|}
\hline Variable & All & Not Married & Married \\
\hline Age in Months & $\begin{array}{l}368.5 \\
(85.2)\end{array}$ & $\begin{array}{l}343.6 \\
(87.2)\end{array}$ & $\begin{array}{l}391.2 \\
(76.5)\end{array}$ \\
\hline Ethnicity: White & $\begin{array}{c}0.968 \\
(0.176)\end{array}$ & $\begin{array}{c}0.955 \\
(0.208)\end{array}$ & $\begin{array}{c}0.980 \\
(0.141)\end{array}$ \\
\hline Ethnicity: Asian & $\begin{array}{c}0.009 \\
(0.095)\end{array}$ & $\begin{array}{c}0.008 \\
(0.090)\end{array}$ & $\begin{array}{c}0.010 \\
(0.099)\end{array}$ \\
\hline Ethnicity: Black & $\begin{array}{c}0.016 \\
(0.126)\end{array}$ & $\begin{array}{c}0.027 \\
(0.161)\end{array}$ & $\begin{array}{c}0.006 \\
(0.080)\end{array}$ \\
\hline Ethnicity: Other & $\begin{array}{c}0.007 \\
(0.083)\end{array}$ & $\begin{array}{c}0.010 \\
(0.101)\end{array}$ & $\begin{array}{c}0.004 \\
(0.062)\end{array}$ \\
\hline Ec. Active & $\begin{array}{c}0.687 \\
(0.464)\end{array}$ & $\begin{array}{c}0.692 \\
(0.462)\end{array}$ & $\begin{array}{c}0.682 \\
(0.466)\end{array}$ \\
\hline No Ac. Qual & $\begin{array}{c}0.209 \\
(0.407)\end{array}$ & $\begin{array}{c}0.225 \\
(0.417)\end{array}$ & $\begin{array}{c}0.195 \\
(0.396)\end{array}$ \\
\hline Level 1 Ac. Qual. & $\begin{array}{c}0.160 \\
(0.366)\end{array}$ & $\begin{array}{c}0.153 \\
(0.360)\end{array}$ & $\begin{array}{c}0.166 \\
(0.372)\end{array}$ \\
\hline Level 2 Ac. Qual. & $\begin{array}{c}0.399 \\
(0.490)\end{array}$ & $\begin{array}{c}0.383 \\
(0.486)\end{array}$ & $\begin{array}{c}0.413 \\
(0.492)\end{array}$ \\
\hline Level 3 Ac. Qual. & $\begin{array}{c}0.113 \\
(0.316)\end{array}$ & $\begin{array}{c}0.123 \\
(0.328)\end{array}$ & $\begin{array}{c}0.104 \\
(0.305)\end{array}$ \\
\hline Level 4 Ac. Qual. & $\begin{array}{c}0.099 \\
(0.298)\end{array}$ & $\begin{array}{c}0.097 \\
(0.296)\end{array}$ & $\begin{array}{c}0.100 \\
(0.300)\end{array}$ \\
\hline Level 5 Ac. Qual. & $\begin{array}{c}0.021 \\
(0.144)\end{array}$ & $\begin{array}{c}0.019 \\
(0.138)\end{array}$ & $\begin{array}{c}0.023 \\
(0.150)\end{array}$ \\
\hline Nr. Obs. & 226,965 & 108,071 & 118,894 \\
\hline
\end{tabular}

Notes: The sample includes women observed in the UK Labour Force Survey 1984-2006, living in England or Wales, born in the UK between September 1957 and August 1971, and aged 18 or above at the time of the survey. 
Table 2: Estimates of Discontinuity in Family Characteristics at January-February Threshold

$\underline{\text { Window }}$

\begin{tabular}{|c|c|c|c|c|c|}
\hline Family Background Variable & Sep-Jun & Oct-May & Nov-Apr & Dec-Mar & Jan-Feb \\
\hline Father's Age at Birth (Months) & $\begin{array}{l}0.811 \\
(0.921)\end{array}$ & $\begin{array}{c}0.474 \\
(1.031)\end{array}$ & $\begin{array}{l}1.207 \\
(1.195)\end{array}$ & $\begin{array}{l}0.572 \\
(1.450)\end{array}$ & $\begin{array}{l}1.250 \\
(2.097)\end{array}$ \\
\hline Mother's Age at Birth (Months) & $\begin{array}{r}-0.557 \\
(0.733)\end{array}$ & $\begin{array}{r}-1.026 \\
(0.820)\end{array}$ & $\begin{array}{c}-0.444 \\
(0.955)\end{array}$ & $\begin{array}{r}-0.442 \\
(1.175)\end{array}$ & $\begin{array}{l}0.987 \\
(1.690)\end{array}$ \\
\hline Father Economically Active & $\begin{array}{l}0.004 \\
(0.004)\end{array}$ & $\begin{array}{r}-0.001 \\
(0.005)\end{array}$ & $\begin{array}{l}-0.005 \\
(0.005)\end{array}$ & $\begin{array}{r}-0.004 \\
(0.007)\end{array}$ & $\begin{array}{r}-0.014 \\
(0.009)\end{array}$ \\
\hline Mother Economically Active & $\begin{array}{l}-0.006 \\
(0.005)\end{array}$ & $\begin{array}{r}-0.005 \\
(0.006)\end{array}$ & $\begin{array}{r}-0.006 \\
(0.007)\end{array}$ & $\begin{array}{r}-0.004 \\
(0.008)\end{array}$ & $\begin{array}{r}-0.002 \\
(0.012)\end{array}$ \\
\hline Father's Highest Ac. Qual. Lev. = 1-2 & $\begin{array}{c}0.011 \\
(0.004)^{* *}\end{array}$ & $\begin{array}{l}0.010 \\
(0.005)^{* *}\end{array}$ & $\begin{array}{l}0.011 \\
(0.006)\end{array}$ & $\begin{array}{l}0.009 \\
(0.007)\end{array}$ & $\begin{array}{l}0.002 \\
(0.010)\end{array}$ \\
\hline Father's Highest Ac. Qual. Lev. = 3 & $\begin{array}{l}0.001 \\
(0.003)\end{array}$ & $\begin{array}{l}0.002 \\
(0.003)\end{array}$ & $\begin{array}{l}0.001 \\
(0.003)\end{array}$ & $\begin{array}{l}0.003 \\
(0.004)\end{array}$ & $\begin{array}{r}-0.001 \\
(0.006)\end{array}$ \\
\hline Father's Highest Ac. Qual. Lev. = 4-5 & $\begin{array}{l}0.012 \\
(0.004)^{* *}\end{array}$ & $\begin{array}{c}0.009 \\
(0.004)^{*}\end{array}$ & $\begin{array}{l}0.016 \\
(0.005)^{* *}\end{array}$ & $\begin{array}{l}0.013 \\
(0.006)^{*}\end{array}$ & $\begin{array}{c}0.017 \\
(0.008)^{*}\end{array}$ \\
\hline Mother's Highest Ac. Qual. Lev. = 1-2 & $\begin{array}{c}0.015 \\
(0.005)^{* *}\end{array}$ & $\begin{array}{l}0.016 \\
(0.005)^{* *}\end{array}$ & $\begin{array}{c}0.016 \\
(0.006)^{* *}\end{array}$ & $\begin{array}{l}0.009 \\
(0.007)\end{array}$ & $\begin{array}{r}-0.008 \\
(0.011)\end{array}$ \\
\hline Mother's Highest Ac. Qual. Lev. = 3 & $\begin{array}{r}-0.002 \\
(0.003)\end{array}$ & $\begin{array}{r}-0.003 \\
(0.003)\end{array}$ & $\begin{array}{r}-0.005 \\
(0.004)\end{array}$ & $\begin{array}{r}-0.004 \\
(0.004)\end{array}$ & $\begin{array}{r}-0.007 \\
(0.006)\end{array}$ \\
\hline Mother's Highest Ac. Qual. Lev. = 4-5 & $\begin{array}{r}-0.000 \\
(0.002)\end{array}$ & $\begin{array}{r}-0.001 \\
(0.002)\end{array}$ & $\begin{array}{l}0.001 \\
(0.003)\end{array}$ & $\begin{array}{c}0.001 \\
(0.003)\end{array}$ & $\begin{array}{c}0.004 \\
(0.005)\end{array}$ \\
\hline Asian & $\begin{array}{l}0.001 \\
(0.002)\end{array}$ & $\begin{array}{l}0.002 \\
(0.002)\end{array}$ & $\begin{array}{l}0.002 \\
(0.002)\end{array}$ & $\begin{array}{l}-0.001 \\
(0.003)\end{array}$ & $\begin{array}{l}0.001 \\
(0.004)\end{array}$ \\
\hline Black & $\begin{array}{l}-0.001 \\
(0.001)\end{array}$ & $\begin{array}{r}-0.001 \\
(0.001)\end{array}$ & $\begin{array}{r}-0.001 \\
(0.002)\end{array}$ & $\begin{array}{r}-0.001 \\
(0.002)\end{array}$ & $\begin{array}{c}0.000 \\
(0.003)\end{array}$ \\
\hline Other Ethnicity & $\begin{array}{c}-0.000 \\
(0.001)\end{array}$ & $\begin{array}{c}0.001 \\
(0.001)\end{array}$ & $\begin{array}{c}-0.000 \\
(0.001)\end{array}$ & $\begin{array}{c}-0.000 \\
(0.002)\end{array}$ & $\begin{array}{c}0.001 \\
(0.003)\end{array}$ \\
\hline
\end{tabular}

Notes: The table reports the estimated coefficients on a dummy for being born in February or later in the academic year in a set of linear regressions where each family characteristics is an outcome variable. Each regression also includes a full set of academic cohort- and survey year dummies. Columns indicate "window size" around the January-February threshold. Significance levels: $* *: 1 \% *: 5 \%$ 
Table 3: Effect of Having Been Required to Stay on on the Probability of Holding Academic Qualification Level $j$ or Above by Window Size.

\section{Window}

\begin{tabular}{lcccc} 
Qual. Lev. & Oct-May & Nov-Apr & Dec-Mar & Jan-Feb \\
\hline Level 1 & $\begin{array}{c}0.036 \\
(0.003)^{* *}\end{array}$ & $\begin{array}{c}0.038 \\
(0.003)^{* *}\end{array}$ & $\begin{array}{c}0.036 \\
(0.003)^{* *}\end{array}$ & $\begin{array}{c}0.037 \\
(0.004)^{* *}\end{array}$ \\
Level 2 & $\begin{array}{c}0.005 \\
(0.003)\end{array}$ & $\begin{array}{c}0.010 \\
(0.003)^{* *}\end{array}$ & $\begin{array}{c}0.010 \\
(0.004)^{* *}\end{array}$ & $\begin{array}{c}0.012 \\
(0.005)^{*}\end{array}$ \\
Level 3 & 0.001 & 0.003 & 0.002 & 0.001 \\
& $(0.003)$ & $(0.003)$ & $(0.003)$ & $(0.004)$ \\
Level 4 & 0.005 & 0.006 & 0.006 & 0.007 \\
& $(0.002)^{*}$ & $(0.002)^{* *}$ & $(0.002)^{*}$ & $(0.003)^{*}$ \\
Level 5 & -0.001 & -0.001 & -0.001 & -0.001 \\
& $(0.001)$ & $(0.001)$ & $(0.001)$ & $(0.001)$ \\
\hline Nr. Obs. & 151,629 & 112,726 & 76,016 & 37,652 \\
\hline \hline
\end{tabular}

Notes: The table reports the estimated coefficients on a dummy for being born in February or later in the academic year in a set of linear regressions where the outcome variable in each case is a dummy for holding an academic qualification at level $j$ or above. All regressions also include a full set of academic cohort dummies, survey year dummies and ethnicity dummies, as well as age measured in months in linear, square and cubic form. Columns indicate "window size" around the January-February threshold. Significance levels: $* *: 1 \% *: 5 \%$ 
Table 4: Effect of Having Been Required to Stay on on the Probability of Leaving Full-Time Education at Various Ages

\begin{tabular}{lccc}
\hline & \multicolumn{3}{c}{ Window } \\
Age Left FTE & Nov-Apr & Dec-Mar & Jan-Feb \\
\hline Age 16 or below & $\begin{array}{c}-0.003 \\
(0.003)\end{array}$ & $\begin{array}{c}-0.005 \\
(0.004)\end{array}$ & $\begin{array}{c}-0.003 \\
(0.005)\end{array}$ \\
& & & \\
Age 17 & -0.003 & -0.001 & 0.000 \\
& $(0.002)$ & $(0.002)$ & $(0.003)$ \\
Age 18 & 0.005 & 0.005 & -0.000 \\
& $(0.002)^{*}$ & $(0.003)$ & $(0.004)$ \\
Age 19 or above & 0.000 & 0.001 & 0.003 \\
& $(0.002)$ & $(0.003)$ & $(0.004)$ \\
\hline Nr. Obs. & 112,726 & 76,016 & 37,652 \\
\hline \hline
\end{tabular}

Notes: The table reports the estimated coefficients on a dummy for being born in February or later in the academic year in a set of linear regressions where the outcome variable in each case is a dummy for having left full time education at age $j$. Each regression also includes a full set of academic cohort dummies, survey year dummies and ethnicity dummies, as well as age measured in months in linear, square and cubic form. Columns indicate "window size" around the January-February threshold. Significance levels: $* *: 1 \% *: 5 \%$. 
Table 5: Estimates of the Effect of Holding an Academic Qualification on the Probability of Being Currently Married among Women Aged 23 or Above.

Window

\begin{tabular}{lccccc} 
Outcome Variable & Sep-Jun & Oct-May & Nov-Apr & Dec-Mar & Jan-Feb \\
\hline OLS & & & & & \\
\multicolumn{1}{c}{ Currently Married } & $\begin{array}{r}0.092 \\
(0.003)^{* *}\end{array}$ & $\begin{array}{c}0.093 \\
(0.003)^{* *}\end{array}$ & $\begin{array}{c}0.089 \\
(0.004)^{* *}\end{array}$ & $\begin{array}{c}0.090 \\
(0.005)^{* *}\end{array}$ & $\begin{array}{c}0.093 \\
(0.006)^{* *}\end{array}$ \\
\hline IV & & & & & \\
\multicolumn{1}{c}{ Currently Married } & -0.051 & -0.011 & -0.049 & -0.011 & 0.068 \\
& $(0.080)$ & $(0.083)$ & $(0.087)$ & $(0.106)$ & $(0.145)$ \\
\hline Nr. Obs. & 159,944 & 128,157 & 95,475 & 64,377 & 31,869 \\
\hline \hline
\end{tabular}

Notes: The table reports the estimated coefficients on a dummy for holding some academic qualification in a set of regressions where in each case the outcome variable is a dummy for being currently married. In the IV regressions, a dummy for being born in February or later in the academic year is used as instrument for holding some academic qualification. Each regression also includes a full set of academic cohort dummies, survey year dummies and ethnicity dummies, as well as age measured in months in linear, square and cubic form. Columns indicate "window size" around the January-February threshold. Significance levels: $* *: 1 \% *: 5 \%$ 
Table 6: Effect of Holding Academic Qualifications on the Probability of Spouse Holding Some Academic Qualification and on the Probability of the Spouse being Economically Active, Estimated by OLS

\begin{tabular}{lcc}
\hline & \multicolumn{2}{c}{ Dependent Variable } \\
Qual. Lev. & Ac. Qual. & Ec. Activity \\
\hline Level 1 & $\begin{array}{c}0.273 \\
(0.004)^{* *}\end{array}$ & $\begin{array}{c}0.116 \\
(0.003)^{* *}\end{array}$ \\
Level 2 & 0.343 & 0.147 \\
& $(0.004)^{* *}$ & $(0.002)^{* *}$ \\
Level 3 & 0.463 & 0.162 \\
& $(0.005)^{* *}$ & $(0.003)^{* *}$ \\
Level 4 & 0.545 & 0.160 \\
& $(0.005)^{* *}$ & $(0.003)^{* *}$ \\
Level 5 & 0.545 & 0.153 \\
& $(0.009)^{* *}$ & $(0.006)^{* *}$ \\
\hline Nr. Obs. & 114,519 & 117,801 \\
\hline \hline
\end{tabular}

Notes: The table reports the estimated coefficients on a set of dummies for the woman holding academic qualification level 1-5 in two regressions where the outcome variables are a dummy for the husband holding some academic qualification and a dummy for the husband being economically active, respectively. All regressions also include a full set of academic cohort dummies, survey year dummies and ethnicity dummies, as well as age measured in months in linear, square and cubic form. Significance levels: $* *: 1 \% *$ : $5 \%$. 
Table 7: Estimates of the Effect of Holding an Academic Qualification on Husband's Economic Characteristics.

\section{Window}

\begin{tabular}{lccccc} 
Outcome Variable & Sep-Jun & Oct-May & Nov-Apr & Dec-Mar & Jan-Feb \\
\hline OLS & & & & & \\
Spouse has Ac. Qual. & 0.371 & 0.370 & 0.369 & 0.369 & 0.366 \\
& $(0.004)^{* *}$ & $(0.004)^{* *}$ & $(0.005)^{* *}$ & $(0.006)^{* *}$ & $(0.008)^{* *}$ \\
Spouse is Ec. Active & 0.146 & 0.143 & 0.141 & 0.135 & 0.145 \\
& $(0.002)^{* *}$ & $(0.003)^{* *}$ & $(0.003)^{* *}$ & $(0.004)^{* *}$ & $(0.005)^{* *}$ \\
\hline IV & & & & & \\
Spouse has Ac. Qual. & 0.218 & 0.183 & 0.273 & 0.264 & 0.250 \\
& $(0.079)^{* *}$ & $(0.082)^{*}$ & $(0.084)^{* *}$ & $(0.105)^{*}$ & $(0.146)$ \\
Spouse is Ec. Active & 0.136 & 0.124 & 0.142 & 0.142 & 0.178 \\
& $(0.052)^{* *}$ & $(0.054)^{*}$ & $(0.057)^{*}$ & $(0.071)^{*}$ & $(0.097)$ \\
\hline Nr. Obs. & 92,267 & 77,048 & 57,000 & 38,360 & 18,977 \\
\hline \hline
\end{tabular}

Notes: The table reports the estimated coefficients on a dummy for holding some academic qualification in a set of regressions with outcome variables as indicated in the table. In the IV regressions, a dummy for being born in February or later in the academic year is used as instrument for holding some academic qualification. Each regression also includes a full set of academic cohort dummies, survey year dummies and ethnicity dummies, as well as age measured in months in linear, square and cubic form. Columns indicate "window size" around the January-February threshold. Significance levels: $* *: 1 \% *: 5 \%$ 
Table 8: Effect of Having Been Required to Stay on Spouse Characteristics by Period

\section{Window}

\begin{tabular}{lccc} 
Variable & Sep-Jun & Nov-Apr & Jan-Feb \\
\hline Spouse holds Academic Qualification & & \\
RTSO*(Ac.Coh. 1952-56) & 0.001 & 0.001 & -0.003 \\
& $(0.005)$ & $(0.006)$ & $(0.010)$ \\
RTSO*(Ac.Coh. 1957-70) & 0.012 & 0.014 & 0.011 \\
& $(0.004)^{* *}$ & $(0.004)^{* *}$ & $(0.007)$ \\
RTSO*(Ac.Coh. 1971-75) & 0.004 & -0.001 & -0.019 \\
& $(0.011)$ & $(0.014)$ & $(0.024)$ \\
Nr. Obs. & 150,099 & 88,890 & 29,490 \\
\hline Spouse is Economically Active & & \\
RTSO*(Ac.Coh. 1952-56) & 0.005 & 0.006 & 0.001 \\
& $(0.003)$ & $(0.004)$ & $(0.006)$ \\
RTSO*(Ac.Coh. 1957-70) & 0.006 & 0.007 & 0.007 \\
& $(0.002)^{* *}$ & $(0.003)^{* *}$ & $(0.004)$ \\
RTSO*(Ac.Coh. 1971-75) & 0.006 & 0.006 & -0.004 \\
& $(0.007)$ & $(0.009)$ & $(0.015)$ \\
Nr. Obs. & 154,314 & 91,386 & 30,350 \\
\hline \hline
\end{tabular}

Notes: The table reports the estimated coefficients on a dummy for being born in February or later in the academic year ("RTSO"), interacted with three dummies indicating subperiod, in a set of linear regressions where the outcome variable, in each case, is a dummy for the husband holding some academic qualification or being economically active. All regressions also include a full set of academic cohort dummies, survey year dummies and ethnicity dummies, as well as age measured in months in linear, square and cubic form. Columns indicate "window size" around the January-February threshold. Significance levels: $* *: 1 \% *: 5 \%$. 

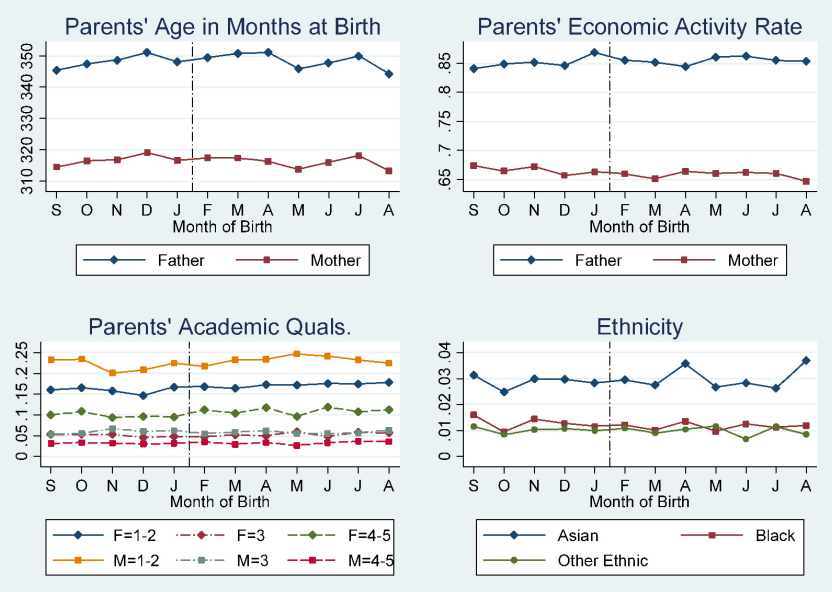

Figure 1: Family Background by Month of Birth

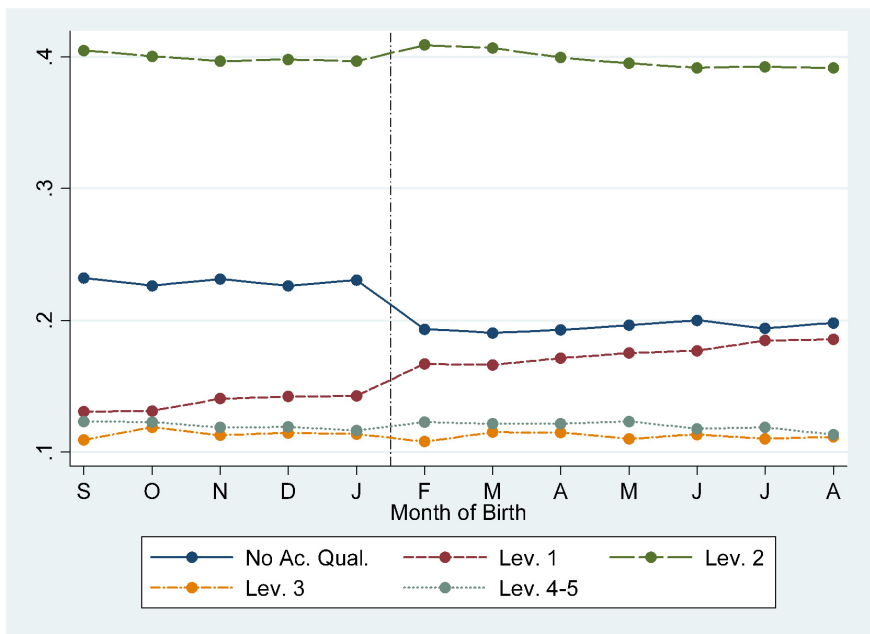

Figure 2: The Distribution of Highest Academic Qualification by Month of Birth 

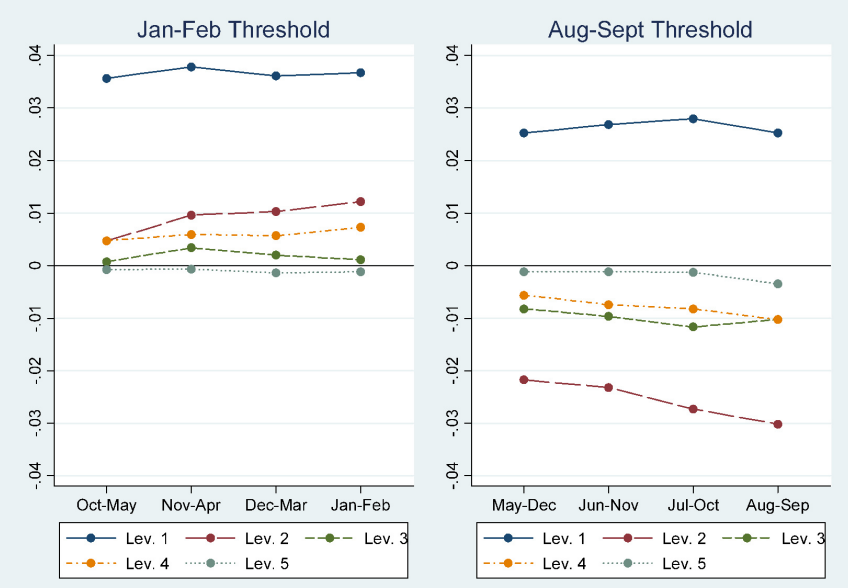

Figure 3: Estimated Effect of Being Required to Stay on on the Probability of Holding Academic Qualification Level $j$ or Above by Threshold Point and Window Size

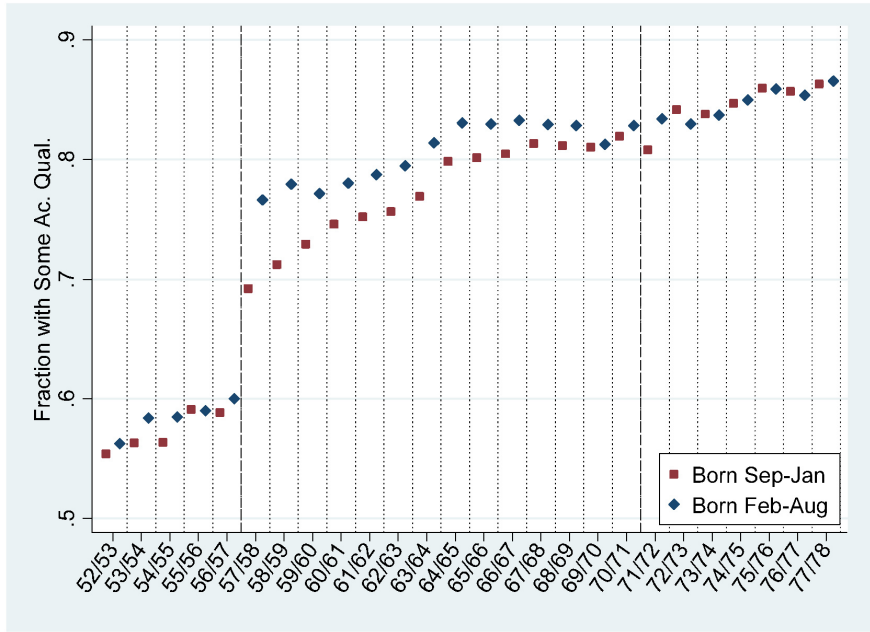

Figure 4: Fraction Holding Some Academic Qualification by Academic Cohort 


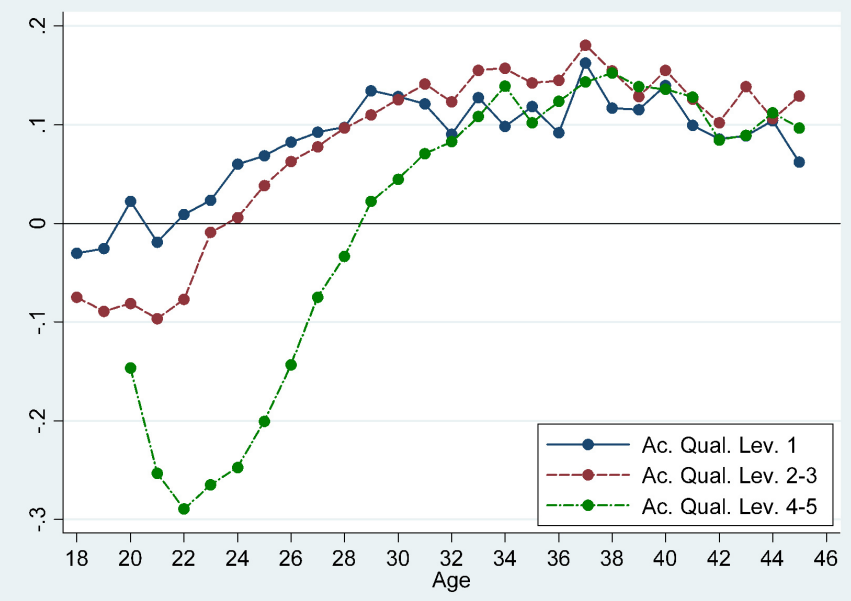

Figure 5: Fraction Currently Married Relative to Individuals with No Academic Qualifications by Age
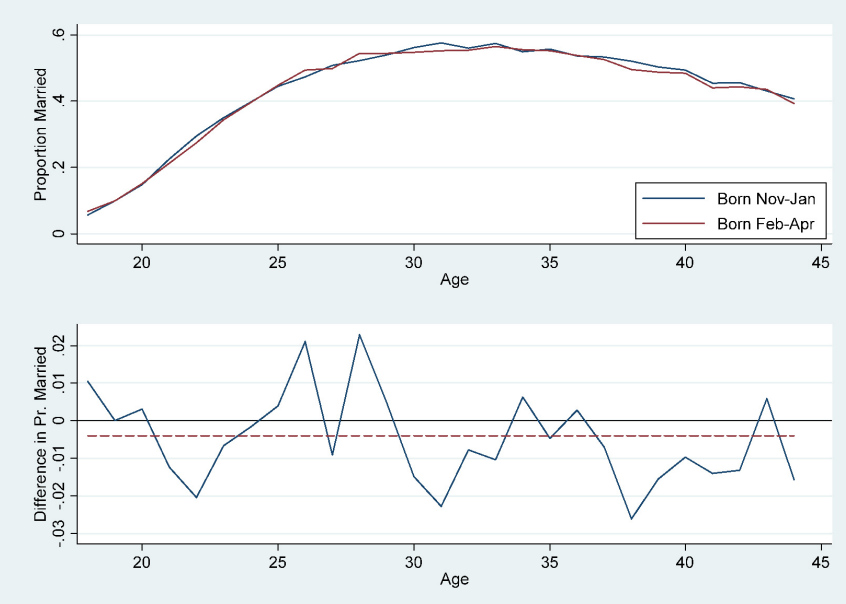

Figure 6: Fraction Currently Married by Requirement to Stay On 

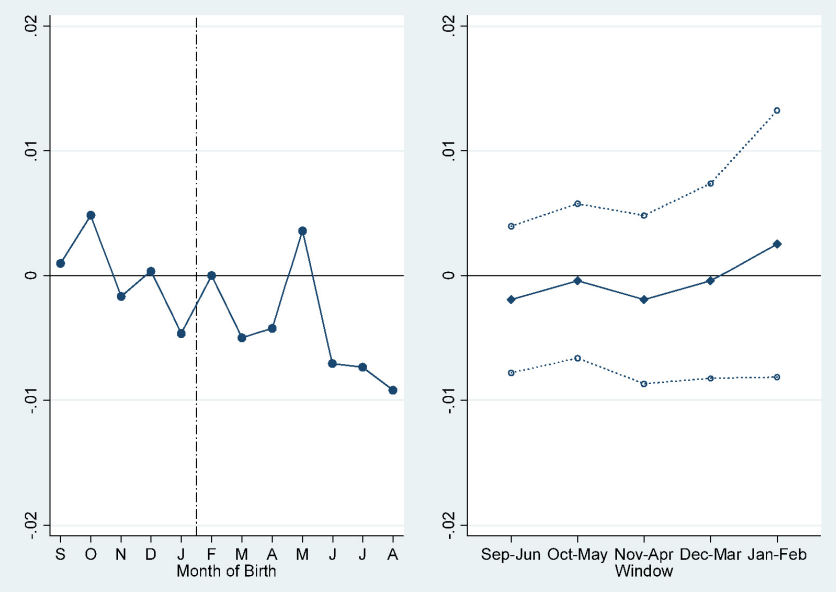

Figure 7: Fraction Currently Married by Month Birth Relative to February, and OLS Estimates of the Difference in Rate of Being Married by Requirement to Stay On, Women Aged 23 and Above
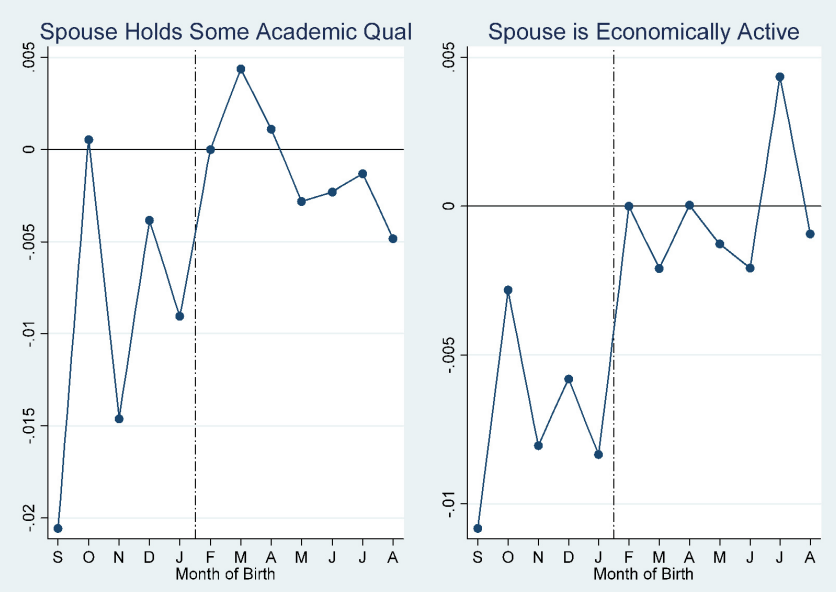

Figure 8: Husbands' Economic Characteristics by Month of Birth of Female Relative to February 

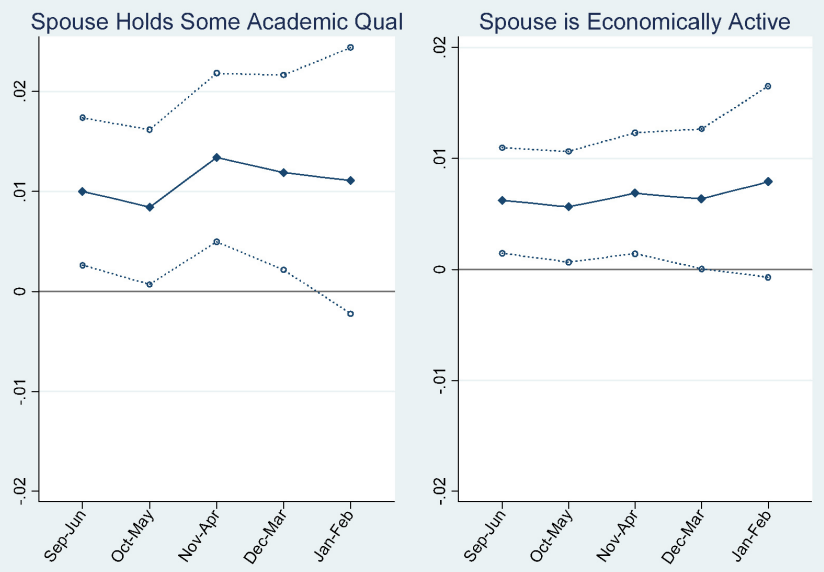

Figure 9: OLS Estimates of the Difference in Husbands' Economic Characteristics by Wife's Requirement to Stay On 


\section{CESifo Working Paper Series}

for full list see www.cesifo-group.org/wp

(address: Poschingerstr. 5, 81679 Munich, Germany, office@cesifo.de)

3041 Matthias Wrede, Multinational Capital Structure and Tax Competition, April 2010

3042 Burkhard Heer and Alfred Maussner, A Note on the Computation of the Equity Premium and the Market Value of Firm Equity, April 2010

3043 Kristiina Huttunen, Jukka Pirttilä and Roope Uusitalo, The Employment Effects of Low-Wage Subsidies, May 2010

3044 Matthias Kalkuhl and Ottmar Edenhofer, Prices vs. Quantities and the Intertemporal Dynamics of the Climate Rent, May 2010

3045 Bruno S. Frey and Lasse Steiner, Pay as you Go: A New Proposal for Museum Pricing, May 2010

3046 Henning Bohn and Charles Stuart, Population under a Cap on Greenhouse Gas Emissions, May 2010

3047 Balázs Égert and Rafal Kierzenkowski, Exports and Property Prices in France: Are they Connected?, May 2010

3048 Thomas Eichner and Thorsten Upmann, Tax-Competition with Involuntary Unemployment, May 2010

3049 Taiji Furusawa, Kazumi Hori and Ian Wooton, A Race beyond the Bottom: The Nature of Bidding for a Firm, May 2010

3050 Xavier Vives, Competition and Stability in Banking, May 2010

3051 Thomas Aronsson and Erkki Koskela, Redistributive Income Taxation under Outsourcing and Foreign Direct Investment, May 2010

3052 Michael Melvin and Duncan Shand, Active Currency Investing and Performance Benchmarks, May 2010

3053 Sören Blomquist and Laurent Simula, Marginal Deadweight Loss when the Income Tax is Nonlinear, May 2010

3054 Lukas Menkhoff, Carol L. Osler and Maik Schmeling, Limit-Order Submission Strategies under Asymmetric Information, May 2010

3055 M. Hashem Pesaran and Alexander Chudik, Econometric Analysis of High Dimensional VARs Featuring a Dominant Unit, May 2010

3056 Rabah Arezki and Frederick van der Ploeg, Do Natural Resources Depress Income Per Capita?, May 2010 
3057 Joseph Plasmans and Ruslan Lukach, The Patterns of Inter-firm and Inter-industry Knowledge Flows in the Netherlands, May 2010

3058 Jenny E. Ligthart and Sebastian E. V. Werner, Has the Euro Affected the Choice of Invoicing Currency?, May 2010

3059 Håkan Selin, Marginal Tax Rates and Tax-Favoured Pension Savings of the SelfEmployed - Evidence from Sweden, May 2010

3060 Richard Cornes, Roger Hartley and Yuji Tamura, A New Approach to Solving Production-Appropriation Games with Many Heterogeneous Players, May 2010

3061 Ronald MacDonald and Flávio Vieira, A Panel Data Investigation of Real Exchange Rate Misalignment and Growth, May 2010

3062 Thomas Eichner and Rüdiger Pethig, Efficient Management of Insecure Fossil Fuel Imports through Taxing(!) Domestic Green Energy?, May 2010

3063 Vít Bubák, Evžen Kočenda and Filip Žikeš, Volatility Transmission in Emerging European Foreign Exchange Markets, May 2010

3064 Leonid V. Azarnert, Après nous le Déluge: Fertility and the Intensity of Struggle against Immigration, May 2010

3065 William E. Becker, William H. Greene and John J. Siegfried, Do Undergraduate Majors or Ph.D. Students Affect Faculty Size?, May 2010

3066 Johannes Becker, Strategic Trade Policy through the Tax System, May 2010

3067 Omer Biran and Françoise Forges, Core-stable Rings in Auctions with Independent Private Values, May 2010

3068 Torben M. Andersen, Why do Scandinavians Work?, May 2010

3069 Andrey Launov and Klaus Wälde, Estimating Incentive and Welfare Effects of NonStationary Unemployment Benefits, May 2010

3070 Simon Gächter, Benedikt Herrmann and Christian Thöni, Culture and Cooperation, June 2010

3071 Mehmet Bac and Eren Inci, The Old-Boy Network and the Quality of Entrepreneurs, June 2010

3072 Krisztina Molnár and Sergio Santoro, Optimal Monetary Policy when Agents are Learning, June 2010

3073 Marcel Boyer and Donatella Porrini, Optimal Liability Sharing and Court Errors: An Exploratory Analysis, June 2010 
3074 Guglielmo Maria Caporale, Roman Matousek and Chris Stewart, EU Banks Rating Assignments: Is there Heterogeneity between New and Old Member Countries? June 2010

3075 Assaf Razin and Efraim Sadka, Fiscal and Migration Competition, June 2010

3076 Shafik Hebous, Martin Ruf and Alfons Weichenrieder, The Effects of Taxation on the Location Decision of Multinational Firms: M\&A vs. Greenfield Investments, June 2010

3077 Alessandro Cigno, How to Deal with Covert Child Labour, and Give Children an Effective Education, in a Poor Developing Country: An Optimal Taxation Problem with Moral Hazard, June 2010

3078 Bruno S. Frey and Lasse Steiner, World Heritage List: Does it Make Sense?, June 2010

3079 Henning Bohn, The Economic Consequences of Rising U.S. Government Debt: Privileges at Risk, June 2010

3080 Rebeca Jiménez-Rodriguez, Amalia Morales-Zumaquero and Balázs Égert, The VARying Effect of Foreign Shocks in Central and Eastern Europe, June 2010

3081 Stephane Dees, M. Hashem Pesaran, L. Vanessa Smith and Ron P. Smith, Supply, Demand and Monetary Policy Shocks in a Multi-Country New Keynesian Model, June 2010

3082 Sara Amoroso, Peter Kort, Bertrand Melenberg, Joseph Plasmans and Mark Vancauteren, Firm Level Productivity under Imperfect Competition in Output and Labor Markets, June 2010

3083 Thomas Eichner and Rüdiger Pethig, International Carbon Emissions Trading and Strategic Incentives to Subsidize Green Energy, June 2010

3084 Henri Fraisse, Labour Disputes and the Game of Legal Representation, June 2010

3085 Andrzej Baniak and Peter Grajzl, Interjurisdictional Linkages and the Scope for Interventionist Legal Harmonization, June 2010

3086 Oliver Falck and Ludger Woessmann, School Competition and Students' Entrepreneurial Intentions: International Evidence Using Historical Catholic Roots of Private Schooling, June 2010

3087 Bernd Hayo and Stefan Voigt, Determinants of Constitutional Change: Why do Countries Change their Form of Government?, June 2010

3088 Momi Dahan and Michel Strawczynski, Fiscal Rules and Composition Bias in OECD Countries, June 2010

3089 Marcel Fratzscher and Julien Reynaud, IMF Surveillance and Financial Markets - A Political Economy Analysis, June 2010 
3090 Michel Beine, Elisabetta Lodigiani and Robert Vermeulen, Remittances and Financial Openness, June 2010

3091 Sebastian Kube and Christian Traxler, The Interaction of Legal and Social Norm Enforcement, June 2010

3092 Volker Grossmann, Thomas M. Steger and Timo Trimborn, Quantifying Optimal Growth Policy, June 2010

3093 Huw David Dixon, A Unified Framework for Using Micro-Data to Compare Dynamic Wage and Price Setting Models, June 2010

3094 Helmuth Cremer, Firouz Gahvari and Pierre Pestieau, Accidental Bequests: A Curse for the Rich and a Boon for the Poor, June 2010

3095 Frank Lichtenberg, The Contribution of Pharmaceutical Innovation to Longevity Growth in Germany and France, June 2010

3096 Simon P. Anderson, Øystein Foros and Hans Jarle Kind, Hotelling Competition with Multi-Purchasing: Time Magazine, Newsweek, or both?, June 2010

3097 Assar Lindbeck and Mats Persson, A Continuous Theory of Income Insurance, June 2010

3098 Thomas Moutos and Christos Tsitsikas, Whither Public Interest: The Case of Greece's Public Finance, June 2010

3099 Thomas Eichner and Thorsten Upmann, Labor Markets and Capital Tax Competition, June 2010

3100 Massimo Bordignon and Santino Piazza, Who do you Blame in Local Finance? An Analysis of Municipal Financing in Italy, June 2010

3101 Kyriakos C. Neanidis, Financial Dollarization and European Union Membership, June 2010

3102 Maela Giofré, Investor Protection and Foreign Stakeholders, June 2010

3103 Andrea F. Presbitero and Alberto Zazzaro, Competition and Relationship Lending: Friends or Foes?, June 2010

3104 Dan Anderberg and Yu Zhu, The Effect of Education on Martial Status and Partner Characteristics: Evidence from the UK, June 2010 